\title{
Spontaneous Oscillation by Hair Bundles of the Bullfrog's Sacculus
}

\author{
Pascal Martin, D. Bozovic, Y. Choe, and A. J. Hudspeth \\ Howard Hughes Medical Institute and Laboratory of Sensory Neuroscience, The Rockefeller University, New York, New York 10021-6399
}

\begin{abstract}
One prominent manifestation of mechanical activity in hair cells is spontaneous otoacoustic emission, the unprovoked emanation of sound by an internal ear. Because active hair bundle motility probably constitutes the active process of nonmammalian hair cells, we investigated the ability of hair bundles in the bullfrog's sacculus to produce oscillations that might underlie spontaneous otoacoustic emissions. When maintained in the normal ionic milieu of the ear, many bundles oscillated spontaneously through distances as great as $80 \mathrm{~nm}$ at frequencies of $5-50 \mathrm{~Hz}$. Whole-cell recording disclosed that the positive phase of movement was associated with the opening of transduction channels. Gentamicin, which blocks transduction channels, reversibly arrested oscillation; drugs that affect the cAMP phosphorylation pathway and might influence the activity of myosin altered the rate of oscillation. Increasing the $\mathrm{Ca}^{2+}$ concentration rendered oscillations faster and smaller until they were suppressed; lowering the $\mathrm{Ca}^{2+}$ concentration moderately with chelators had the opposite effect. When a bundle was offset with a stimulus fiber, oscillations were transiently suppressed but gradually resumed. Loading a bundle by partial displacement clamping, which simulated the presence of the accessory structures to which a bundle is ordinarily attached, increased the frequency and diminished the magnitude of oscillation. These observations accord with a model in which oscillations arise from the interplay of the hair bundle's negative stiffness with the activity of adaptation motors and with $\mathrm{Ca}^{2+}-$ dependent relaxation of gating springs.
\end{abstract}

Key words: adaptation; amplification; auditory system; mechanoelectrical transduction; negative stiffness; vestibular system

\section{Introduction}

The ear is mechanically active. Whether spontaneous or evoked by sound, otoacoustic emissions constitute the most striking evidence that energy-consuming elements within the inner ear can produce work. The ear's ability to deliver metabolically powered forces results in mechanical amplification: for sound stimuli near threshold, the active process augments vibrations in the mammalian cochlea by $>100$-fold, thus countering the dissipation caused by viscous drag in the fluid of the inner ear. Amplification of faint stimuli is closely associated with sharp frequency selectivity, because each portion of a receptor organ acts as a highly tuned mechanical resonator that responds preferentially at a natural frequency. Finally, the response of the ear to stimuli of increasing magnitude grows nonlinearly; the basilar membrane of the chinchilla, for example, represents six decades of sound pressure by only two orders of magnitude of vibration (Ruggero et al., 1997). Otoacoustic emissions, amplification, frequency selectivity, and compressive nonlinearity represent four essential characteristics of the active process that enhances detection of mechanical stimuli by the vertebrate inner ear (for review, see Manley, 2000, 2001).

Received Nov. 14, 2002; revised March 12, 2003; accepted March 14, 2003.

This work was supported by National Institutes of Health Grant DC00241. P.M. was an associate, D.B. is an associate, and A.J.H. is an investigator of the Howard Hughes Medical Institute. We thank B. Fabella for computer programming and Dr. A. Mehta and L. Chemes for assistance in some experiments. Dr. F. Jülicher, Dr. L. Le Goff, Dr. J. Prost, L. Chemes, E. Chiappe, and D. Chan provided helpful comments on this manuscript.

Correspondence should be addressed to Dr. A. J. Hudspeth, Howard Hughes Medical Institute and Laboratory of Sensory Neuroscience, Box 314, The Rockefeller University, 1230 York Avenue, New York, NY 10021-6399. E-mail: hudspaj@rockefeller.edu.

P. Martin's present address: Laboratoire Physico-Chimie Curie, Institut Curie, 26 rue d'Ulm, F-75248 Paris Cedex 05, France.

Copyright $\odot 2003$ Society for Neuroscience $\quad$ 0270-6474/03/234533-16\$15.00/0
Although amplification in the mammalian cochlea is widely believed to involve membrane-based electromotility by outer hair cells (reviewed in Dallos, 1992; Nobili et al., 1998), the receptor organs of amphibians, reptiles, and birds are not endowed with electromotile cells (He et al., 2003). The ears of nonmammalian tetrapods nevertheless display all four characteristics of the active process (for review, see Manley and Köppl, 1998; Manley, 2000, 2001). The alternative mechanism proposed to underlie the active process in those animals, and perhaps in mammals as well, is active hair bundle motility (for review, see Hudspeth, 1997; Hudspeth et al., 2000; Fettiplace et al., 2001). This process displays the four hallmarks of the active process (Martin and Hudspeth, 2001). A bundle can oscillate spontaneously (Crawford and Fettiplace, 1985; Howard and Hudspeth, 1987a; Denk and Webb, 1992; Benser et al., 1996; Martin and Hudspeth, 1999, 2001; Martin et al., 2000, 2001), a behavior that might underlie spontaneous otoacoustic emissions. The power expended by an oscillating bundle can be funneled into a weak sinusoidal stimulus to amplify the input (Martin and Hudspeth, 1999, 2001). The sensitivity of a bundle is tuned, with the greatest responsiveness at its natural frequency (Martin et al., 2001). Finally, the response of a hair bundle at its natural frequency displays a compressive nonlinearity (Martin and Hudspeth, 2001).

The four characteristics that define the aural active process are signatures of a dynamical system operating near a Hopf bifurcation (Choe et al., 1998; Camalet et al., 2000; Eguíluz et al., 2000; Jülicher et al., 2001; Martin et al., 2001). Such an oscillatory instability may emerge from the interplay of the negative stiffness of a hair bundle (Martin et al., 2000) with the molecular motors responsible for mechanical adaptation (for review, see Hudspeth and Gillespie, 1994; Eatock, 2000; Holt and Corey, 2000). To 
strengthen the evidence that this mechanism can mediate active hair bundle movements, we have examined the effects of treatments that affect the mechanical properties of a bundle and the adaptation motor on the ability of a hair cell to oscillate spontaneously.

\section{Materials and Methods}

Experimental preparation. Experiments were performed at a room temperature of $\sim 21^{\circ} \mathrm{C}$ on saccular hair cells from the bullfrog Rana catesbeiana. Each internal ear was dissected in oxygenated standard saline solution containing (in mM): $110 \mathrm{Na}^{+}, 2 \mathrm{~K}^{+}, 4 \mathrm{Ca}^{2+}, 122 \mathrm{Cl}^{-}, 3 \mathrm{D}$-glucose, and 5 HEPES. After dissection from the labyrinth, the saccular macula was mounted over a $1 \mathrm{~mm}$ hole in a plastic coverslip and secured around the edges of its basal aspect with tissue-compatible acrylic adhesive (Isodent; Ellman International, Hewlett, NY). While the basolateral surface remained in contact with standard saline solution, the otolithic membrane was loosened by a 30 min exposure of the apical surface to $40 \mu \mathrm{g} / \mathrm{ml}$ protease type XXIV in $\mathrm{N}$-methyl-D-glucamine (NMDG) endolymph containing (in mM): $2 \mathrm{Na}^{+}, 3 \mathrm{~K}^{+}, 0.25 \mathrm{Ca}^{2+}, 110 \mathrm{NMDG}, 111 \mathrm{Cl}^{-}, 3$ D-glucose, and 5 HEPES. The otolithic membrane was then lifted from the hair bundles, and the coverslip was secured in a two-compartment experimental chamber (Martin and Hudspeth, 1999).

During most experiments, the standard saline solution in the lower compartment was not exchanged. The upper compartment ordinarily contained oxygenated NMDG endolymph; except when specifically indicated, the results presented here were obtained in the presence of this solution. Some experiments instead used artificial endolymph containing (in mM): $2 \mathrm{Na}^{+}, 118 \mathrm{~K}^{+}, 0.25 \mathrm{Ca}^{2+}, 118 \mathrm{Cl}^{-}, 3 \mathrm{D}$-glucose, and 5 HEPES. Each solution had a pH of $\sim 7.3$ and an osmotic strength of $\sim 230$ $\mathrm{mmol} / \mathrm{kg}$.

Enzymes, drugs, and other chemicals were obtained from Sigma (St. Louis, MO).

Kinociliary dissection. After control recordings had been made, kinocilia were detached from individual hair bundles with a horizontally mounted glass microelectrode (Hudspeth and Jacobs, 1979). The tip of the electrode was situated about halfway up the bundle and insinuated between the kinocilium and the remainder of the bundle. Moving the electrode upward then severed the filamentous connections between the kinociliary bulb and the five tallest stereocilia (Hillman and Lewis, 1971; Jacobs and Hudspeth, 1990). While additional mechanical recordings were made with the stimulus fiber resting atop the stereociliary cluster, the electrode was used to hold the loosened kinocilium flat against the epithelial surface.

Iontophoresis of $\mathrm{Ca}^{2+}$ and drugs. Iontophoresis was used to apply several substances to hair bundles during measurement of their spontaneous oscillation and stiffness. In each instance, a coarse microelectrode, whose resistance would have been $\sim 5 \mathrm{M} \Omega$ if filled with $3 \mathrm{M} \mathrm{KCl}$, was fabricated with a patch-electrode puller (L/M-3P-A; List Electronic, Darmstadt, Germany). After having been bent through an angle of $\sim 45^{\circ}$ in its tapered region, the electrode was filled with $2.5 \mathrm{M} \mathrm{CaCl}_{2}, 350 \mathrm{~mm}$ disodium ATP, or $500 \mathrm{~mm}$ gentamicin sulfate. The tip of the pipette was then situated over the hair cell under investigation, $\sim 3 \mu \mathrm{m}$ above the top of the bundle, and oriented toward the bundle. An appropriate holding current was used in each instance to minimize diffusive release of the contents of the electrode under control conditions.

Tight-seal electrical recording. We used the perforated patch recording technique with a voltage-clamp amplifier (Axopatch 200B; Axon Instruments, Union City, CA) to measure transduction currents in spontaneously oscillating hair cells. Tight-seal electrodes were drawn with a pipette puller (L/M-3P-A, List Electronic), bent to permit an orthogonal approach to the apical surface of a cell, and heat-polished to give resistances of 5-10 M $\Omega$. The tip of each recording electrode was positioned with a Huxley micromanipulator on the apical surface of a hair cell opposite the kinocilium (Holton and Hudspeth, 1986).

Each recording pipette was tip-filled for $\sim 1 \mathrm{sec}$ with a solution containing (in mM): $110 \mathrm{Cs}^{+}, 3 \mathrm{Mg}^{2+}, 20$ spermine, $114 \mathrm{Cl}^{-}, 40 \mathrm{SO}_{4}{ }^{2-}$, and 5 HEPES. The pipette was then back-filled with an identical solution supplemented with $260 \mu \mathrm{M}$ amphotericin B that had been dissolved in
DMSO, whose concentration in the internal solution was $2 \%(\mathrm{v} / \mathrm{v})$. When used in the presence of artificial endolymph, this internal solution produced a liquid-junction potential of $\sim 0 \mathrm{mV}$. A polycationic molecule, spermine, was included in the internal solution because of the difficulty in creating tight seals on the apical membrane of hair cells (Holton and Hudspeth, 1986). The presence of spermine permitted the formation of tight seals within several seconds of applied suction. Like its precursor spermidine, this polyamine occurs in cytoplasm at a concentration of $\sim 1$ $\mathrm{mm}$ as an important counterion to RNA (Igarashi and Kashiwagi, 2000). The transduction currents measured in the presence of spermine did not differ in magnitude from those recorded from isolated hair cells (Jaramillo and Hudspeth, 1991; Assad and Corey, 1992; Shepherd and Corey, 1994; Walker and Hudspeth, 1996; Lumpkin and Hudspeth, 1998), for which no special treatment is required to make tight seals. Moreover, control recordings earlier demonstrated no untoward effects of lower concentrations of spermine and spermidine (Holton and Hudspeth, 1986). Because the membrane potential of a hair cell was held either at the resting potential ascertained under current-clamp conditions or at -70 $\mathrm{mV}$, transduction currents were always inward and it is improbable that a cation such as spermine would have significantly blocked transduction channels.

Microscopic apparatus. Experiments were conducted under an upright microscope (MPS; Zeiss, Jena, Germany) equipped with a $100 \mathrm{~W}$ mercury illuminator, an infrared-reflecting hot mirror (K43-842; Edmund Industrial Optics, Barrington, NJ), and a broadband green interference filter (500 $\pm 40 \mathrm{~nm}$, half-width at half-maximal transmittance; K46-157; Edmund Industrial Optics). The image formed by a $40 \times$ water immersion objective lens of numerical aperture 0.75 was further magnified by a $1.6 \times$ relay lens. Observations by eye and video microscopy were made with differential interference contrast optics. To increase the signal reaching the photodiodes, the analyzer was relocated from the microscope tube to the eyepiece assembly; moreover, during measurements of hair bundle motion, the polarizer was removed.

Because spontaneous hair bundle movements were sometimes too small or too fast to be detected directly by eye, we also used video microscopy to locate spontaneously active bundles. The image provided by the microscope was relayed through a projection eyepiece of $125 \mathrm{~mm}$ focal length or by a $1.5 \times$ telescope to a charge-coupled-device camera whose field of view encompassed several hair bundles. Its output was directed to a video image processor (Argus-20; Hamamatsu Photonics, Hamamatsu City, Japan). To highlight hair bundle oscillations, we digitally subtracted from each frame the running average of several consecutive frames.

Mechanical stimulation. Mechanical stimuli were delivered by a flexible glass fiber whose tip was attached to the kinociliary bulb of an individual hair bundle. Fibers were fabricated from borosilicate capillaries of 1.2 mm diameter (TW120-3, World Precision Instruments). Each capillary was first reduced with an electrode puller (P-80/PC; Sutter Instruments, Novato, CA) and then pulled finer in a direction perpendicular to its shank with a $120 \mathrm{~V}$ solenoid (Howard and Hudspeth, 1988). We found that a fiber of $\sim 500 \mathrm{~nm}$ in diameter was best for attachment to the kinociliary bulb. The fiber was trimmed with iridectomy scissors to a length of 100-400 $\mu \mathrm{m}$. To enhance optical contrast, we coated the fiber with an $\sim 100 \mathrm{~nm}$ layer of gold-palladium (Hummer VI; Anatech, Alexandria, VA). The stiffness and drag coefficient of the fiber were, respectively, $80-400 \mu \mathrm{N} \cdot \mathrm{m}^{-1}$ and $40-110 \mathrm{nN} \cdot \mathrm{sec} \cdot \mathrm{m}^{-1}$, as determined by power spectral analysis of Brownian motion of the tip of the fiber in water. The fiber behaved as a first-order low-pass mechanical filter with a cutoff frequency of $0.2-1.6 \mathrm{kHz}$.

The fiber was secured by its base to a stack-type piezoelectric actuator (P835.10; Physik Instrumente) driven by a matched power supply (P870; Physik Instrumente); this actuator provided displacements up to \pm 1 $\mu \mathrm{m}$ with a bandwidth of $5 \mathrm{kHz}$. The piezoelectric actuator was in turn mounted on a Huxley micromanipulator, which allowed fine positioning of the tip of the fiber with a submicrometer resolution. The fiber was used both to apply stimuli at the top of a hair bundle and to report bundle movements. Holding the base of the fiber at a fixed position permitted accurate measurement of the spontaneous motion of the bundle.

Displacement monitor. The tip of the fiber was imaged at a magnification of $1000 \times$ on a dual photodiode (UV-140-2; EG\&G Electro-Optics, 
Salem, MA). A pair of preamplifiers directly attached to the photodiodes provided current-to-voltage conversion with a gain of $10^{7}$. After the difference between the electrical signals from the two photodiodes had been computed, the displacement monitor yielded an output linearly proportional to the displacement of the tip of the fiber with a resolution of $\sim 1 \mathrm{~nm}$. To allow centering of the image of the fiber on the detector, the dual photodiode and preamplifier were mounted on a two-axis linear stage equipped with a stepping motor microdrive and controller (B-05 and PMC100; Newport, Irvine, CA). The photometric apparatus was placed on an independent platform mounted above the air table holding the microscope.

For calibration purposes, the photometric system was additionally secured to a piezoelectric stimulator. Each experimental record was calibrated by imposing a $20 \mu \mathrm{m}$ offset pulse on the dual photodiode. Because of the optical magnification of the imaging system, the resultant output signal from the photodiodes was equivalent to that attributable to a $20 \mathrm{~nm}$ displacement of the stimulus fiber. The photodiode offset system was in turn calibrated with a heterodyne interferometer (OFV3001; Polytec $\mathrm{GmbH}$, Waldbronn, Germany).

Displacement-clamp measurements. We used negative feedback to ensure that the bundle position, $X(t)$, matched a command position, $X_{C}(t)$ (Jaramillo and Hudspeth, 1993; Benser et al., 1996). The feedback signal, obtained by comparing the position of the bundle to the command signal, provided the input to the piezoelectric stimulator that moved the base of the fiber by a distance $\Delta(t)$. It follows that:

$$
\tilde{\Delta}(\omega)=\tilde{G}(\omega)\left[\tilde{X}_{\mathrm{C}}(\omega)-\tilde{X}(\omega)\right]
$$

in which $\tilde{G}(\omega)$ defines the gain of the clamp circuit at the angular frequency $\omega$, and tildes denote the Fourier transforms of variables. In addition to proportional gain, which does not depend on frequency, we added integral gain to counter slow drifts in the position of the bundle and differential gain to dampen high-frequency components of the movement of the bundle. To prevent instabilities, the feedback signal sent to the piezoelectric stimulator was further filtered using a single-pole low-pass filter. The complex gain function thus assumes the form:

$$
\tilde{G}(\omega)=\frac{A}{1+j\left(\frac{\omega}{\omega_{1}}\right)}\left[G_{\mathrm{P}}+\frac{G_{1}}{1+j\left(\frac{\omega}{\omega_{2}}\right)}+\frac{j G_{\mathrm{D}}\left(\frac{\omega}{\omega_{3}}\right)}{1+j\left(\frac{\omega}{\omega_{4}}\right)}\right],
$$

in which the scaling factor $A \sim 10$, and the corner frequencies $\omega_{1}=400$ $\mathrm{sec}^{-1} ; \omega_{2}=3 \mathrm{sec}^{-1} ; \omega_{3}=10,000 \mathrm{sec}^{-1} ;$ and $\omega_{4}=1000 \mathrm{sec}^{-1}$. Before each experiment, the magnitudes of the proportional gain $G_{\mathrm{P}}$, the integral gain $G_{\mathrm{I}}$, and the derivative gain $G_{\mathrm{D}}$ were set manually to bring the spontaneous oscillation of a bundle to a complete halt; the maximal values of the respective gains were $G_{\mathrm{P}}=12.5, G_{\mathrm{I}}=77$, and $G_{\mathrm{D}}=50$. We then applied a $100 \mathrm{~nm}$ test command pulse and adjusted the gain of the clamp to achieve the bundle movement that reflected the command most faithfully. For the partial-displacement-clamp experiments, the gain of the clamp was controlled electrically by the computer. The clamp circuit was able to track command steps with a time constant of $\sim 1 \mathrm{msec}$.

For measurements of the negative stiffness of a hair bundle, we recorded the forces necessary to displace the bundle through various distances under displacement-clamp control and plotted the relation between displacement and applied force (Martin et al., 2000).

We used partial displacement clamping to study the effect of varying elastic loads on the spontaneous oscillation of a bundle. In this procedure, the movement imposed on the base of the stimulus fiber opposed but did not completely arrest that of a spontaneously oscillating bundle. More specifically, the signal sent to the piezoelectric stimulator consisted of only a fraction of the feedback required to clamp the bundle completely. Neglecting viscous components, the force, $F_{\mathrm{SF}}$, exerted by the stimulus fiber against the hair bundle was proportional to the deflection of the fiber:

$$
F_{\mathrm{SF}}(t)=K_{\mathrm{SF}}[\Delta(t)-X(t)]
$$

in which $K_{\mathrm{SF}}$ represents the stiffness of the stimulus fiber. In combination with Equation 1 for $X_{\mathrm{C}}=0$, the Fourier transform of Equation 3 yields:

$$
\tilde{F}_{\mathrm{SF}}(\omega)=-\tilde{K}_{\mathrm{EFF}}(\omega) \tilde{X}(\omega),
$$

in which $\tilde{K}_{\mathrm{EFF}}(\omega)=K_{\mathrm{SF}}[1+\tilde{G}(\omega)]$ defines the impedance of the fiber at angular frequency $\omega$. Because $\left|\tilde{K}_{\mathrm{EFF}}\right|$ exceeds $K_{\mathrm{SF}}$ at any frequency, the clamp circuit effectively stiffened the fiber in the frequency range over which the feedback circuit operated. Although the impedance of the fiber depended on frequency, it remained approximately constant at frequencies from a few hertz to $\sim 50 \mathrm{~Hz}$ with the parameter settings used in these experiments. Because most of the spectral power of the oscillation of a bundle lay within this frequency band, the fiber effectively provided a linear stiffness.

Data collection and analysis. Stimulation and recording were performed under the control of a computer (P6400 GX1; Dell Computer Corp., Round Rock, TX) running LabVIEW software, version 5.0 (National Instruments, Austin, TX). Stimulus commands and experimental control signals were provided by a dedicated interface (AT-AO-10; National Instruments). Before sampling, responses were low-pass-filtered with an eight-pole Bessel antialiasing filter adjusted to a half-power frequency of $1 \mathrm{kHz}$. A multipurpose interface card (PCI-MIO-16E-1; National Instruments) conducted signal acquisition and analog-to-digital conversion with a precision of 12 bits and a sampling rate of $2.5 \mathrm{kHz}$.

To characterize the spontaneous oscillation of a hair bundle, we computed its power spectrum and fitted it with a Lorentzian function (Martin et al., 2001). The peak frequency of the best fit defined the frequency of the oscillation, and the half-width of the Lorentzian at half its maximal value described the extent of frequency fluctuation.

Data were analyzed with Mathematica, version 4.0 (Wolfram Research, Inc., Champaign, IL) and Matlab, version 6.0 (The MathWorks, Natick, MA).

\section{Results}

\section{Spontaneous hair bundle oscillation}

When mounted in a two-compartment experimental chamber with artificial endolymph or NMDG endolymph bathing the apical surface and standard saline solution contacting the basolateral aspect, the saccular macula from a bullfrog remained healthy for several hours. In most preparations, hair bundles were observed by eye to undergo spontaneous oscillations. In occasional preparations, all of the dozen or so hair bundles within a microscopic field of view could be seen to oscillate. The movements could also be documented by video microscopy. Slow-motion replay revealed fast bundle strokes that looked like instant jumps for a video acquisition rate of 30 frames per second; after each stroke, the bundle remained nearly still before it leapt back in the opposite direction. Subtraction of successive video frames clearly revealed the two components of the motion of a hair bundle in each direction (Fig. 1).

We monitored the movement of an individual hair bundle by attaching the distal end of a fine glass fiber to the top of its kinocilium and projecting an enlarged image of the tip of the fiber onto a dual photodiode. Although loading a hair bundle with a fiber affects the amplitude and frequency of the oscillation (see below), the use of a very flexible fiber minimized this interference and allowed accurate measurement of the dynamical behavior of a bundle.

Different bundles were observed to oscillate spontaneously at frequencies of 5-50 Hz with a peak-to-peak magnitude of motion as great as $80 \mathrm{~nm}$ but most commonly $\sim 25 \mathrm{~nm}$ (Fig. 2). There was no rigorous correlation between the frequency and magnitude of spontaneous movements by different hair bundles. Two hair bundles that oscillated at frequencies almost an order of magnitude apart displayed movements of similar magnitudes (Fig. $2 A, G)$. The slow oscillations were often the largest, however, 

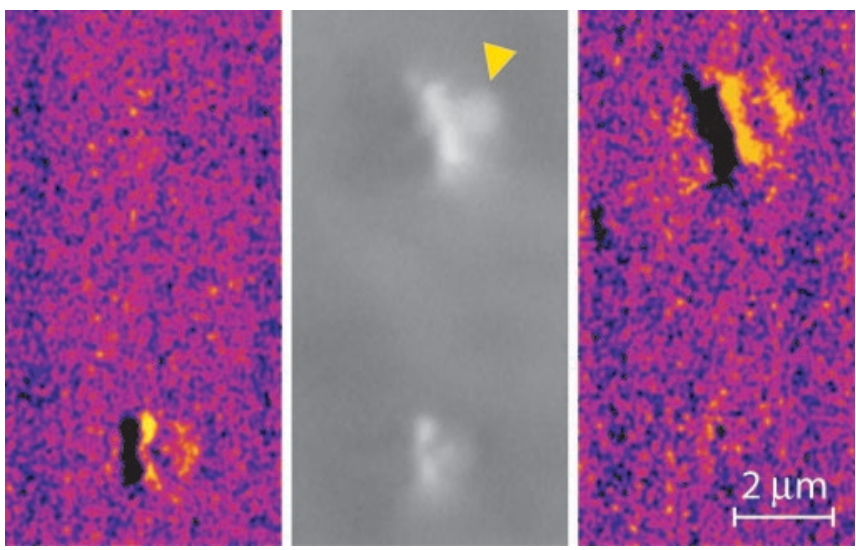

Figure 1. Spontaneous oscillation of hair bundles from the bullfrog's sacculus. The center panel shows one frame from a video movie of a microscopic field encompassing two hair bundles; the arrowhead marks the kinociliary bulb of the upper bundle. Subtraction of this frame from that antecedent produced the false-color image shown at the left, in which it is apparent that the medium-sized bottom hair bundle moved during the $33 \mathrm{msec}$ interval. A similar subtraction of the following frame yielded the right panel, which demonstrates abrupt motion of the large top hair bundle. Movement of a hair bundle toward its tall edge, and thus toward the kinocilium, to the right, is defined as positive in sign and is displayed as an upward deflection in all subsequent figures.

especially for a given hair bundle. We sometimes observed an oscillation that reversibly changed its behavior within short periods. A hair bundle that initially oscillated at $\sim 44 \mathrm{~Hz}$, for instance, displayed movements at $\sim 28 \mathrm{~Hz} 1$ min later before almost doubling its frequency to $\sim 53 \mathrm{~Hz}$ after another $1 \mathrm{~min}$ had elapsed (data not shown). Correspondingly, the amplitude of oscillation increased from 18 to $30 \mathrm{~nm}$ before returning to $16 \mathrm{~nm}$. Some bundles produced movements of almost metronomic regularity (Fig. 2A,B); others moved sporadically and occasionally halted for variable intervals (Fig. $2 C$ ).

Particularly for hair bundles that moved regularly and at relatively low frequencies, it was apparent that each cycle of spontaneous oscillation comprised movements on two time scales (Martin et al., 2000), a behavior typical of a relaxation oscillation (Strogatz, 1994). In each half-cycle, a rapid stroke was followed by a slow excursion in the same direction (Fig. $2 E$ ). The fast component generally consisted of a displacement lasting no more than $5 \mathrm{msec}$. The shape of the slower component varied from cell to cell. In some instances, the movement was nearly exponential (Fig. 2E). On other occasions, the bundle was almost stationary during this component (Fig. $2 F$ ). Finally, the trajectory was often more complex and sometimes even nonmonotonic (Fig. 2D, G). Moreover, the waveforms of the positively and the negatively directed slow components were often dissimilar (Fig. 2C,D).

\section{Relation of channel open probability to spontaneous oscillation}

By making tight-seal voltage-clamp recordings, we were able to measure changes in transduction current associated with the movement of hair bundles. In 10 spontaneously oscillatory hair cells, but not static ones, the current displayed well defined oscillations $\sim 100 \mathrm{pA}$ in peak-to-peak magnitude. Like spontaneous hair bundle displacements, slow current oscillations alternated between rapid transitions and relatively static intervals (data not shown).

We were able to make simultaneous tight-seal electrical recordings and mechanical measurements from one hair cell and

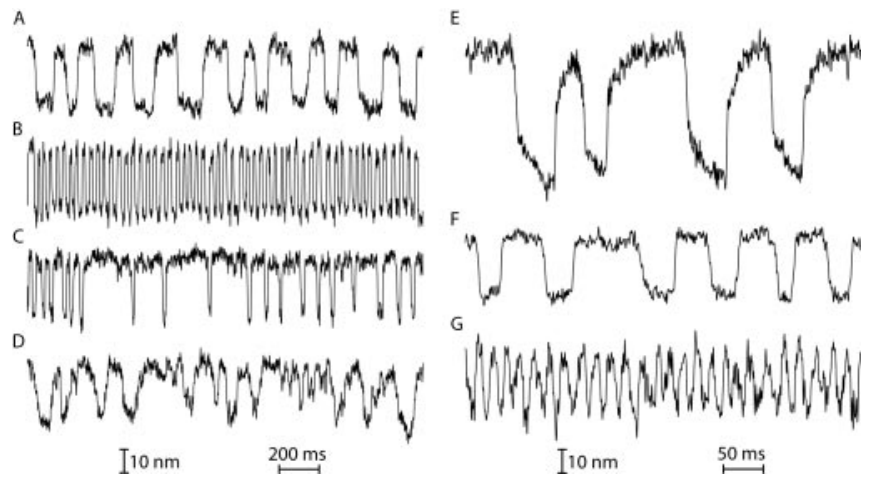

Figure 2. Varieties of spontaneous hair bundle oscillations. A, For a common pattern of regular low-frequency movement, in this instance at $6 \pm 2 \mathrm{~Hz}$, the rms magnitude was $18 \mathrm{~nm}$. $B$, This bundle produced a highly regular, relatively high-frequency oscillation at $27 \pm 3 \mathrm{~Hz}$ with an $18 \mathrm{~nm}$ rms magnitude. C, Some bundles showed variations in oscillation frequency or even occasional pauses in their motion. In this example, the oscillation occurred at $18 \pm 9 \mathrm{~Hz}$, and its rms magnitude was $13 \mathrm{~nm}$. D, The spontaneous movement of this bundle was irregular both in frequency, $6 \pm 3 \mathrm{~Hz}$, and in waveform. Its rms magnitude was $12 \mathrm{~nm}$. Even for a hair bundle capable of regular oscillation, a similar pattern could occur when the recording fiber was poorly attached to the bundle. $E$, Low-frequency oscillations, especially large ones, displayed two clear components during each phase of movement. In each half-cycle, a fast stroke of movement in one direction concluded with a slower component in the same direction. This oscillation was characterized by an exceptionally large rms magnitude of $30 \mathrm{~nm}$ and a frequency of $9 \pm 4 \mathrm{~Hz}$. F, Low-frequency oscillations could be relatively rectilinear. The rms magnitude of this oscillation was $16 \mathrm{~nm}$, and the frequency was $11 \pm 3 \mathrm{~Hz}$. G, The waveform of a relatively high-frequency oscillation, here $53 \pm 6 \mathrm{~Hz}$, could not be parsed into fast and slow components. The rms magnitude of this oscillation was $15 \mathrm{~nm}$.

therefore to examine the relation of transduction channel gating to bundle movement. The transduction current was highly correlated with the phase of spontaneous bundle movement. Positive bundle motion corresponded to an increase in the inward transduction current, whereas negatively directed motion coincided with decreased current (Fig. 3A). Within the temporal resolution of the mechanical and electrical recording techniques, the rapid components of bundle movement and the quick steps in transduction current occurred simultaneously. Because the current oscillations were eliminated by saturating mechanical stimuli, they represented the activity of mechanoelectrical transduction channels.

By applying large mechanical stimuli of both polarities to the hair bundle, we were able to determine the maximal transduction current with all channels open and the zero current with all channels shut (Fig. 3B). Comparison of these values with the extreme values of the transduction current measured during spontaneous oscillation revealed that the open probability varied between 0.13 and 0.70 in this spontaneously active cell.

On excitation with current pulses, a hair cell from the bullfrog's sacculus displays damped oscillations of its membrane potential, a phenomenon termed electrical resonance. Hair cells are also capable of spontaneous electrical oscillation in the absence of stimulation. Because changing the membrane potential of a hair cell evokes bundle movements (Assad and Corey, 1992; Denk and Webb, 1992; Ricci et al., 2000, 2002; Bozovic and Hudspeth, 2003), we were concerned that hair bundle oscillation might have been the result, rather than the source, of an electrical oscillation in the soma of the hair cell. Our observation that hair bundle oscillations remain under voltage-clamp circumstances demonstrates that electrical resonance is not involved in their production. 


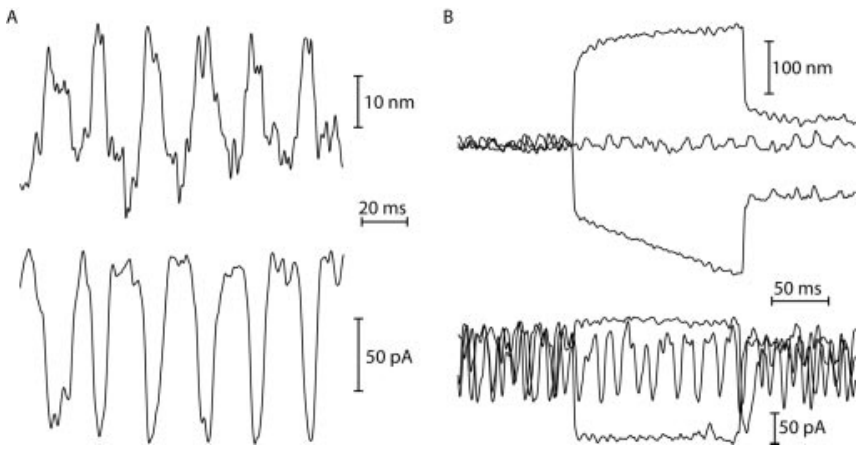

Figure 3. Correlation of spontaneous hair bundle oscillation with channel open probability. $A$, Positive movements of a hair bundle (top record) were associated with inward transduction current, shown as a downward deflection (bottom record). This hair cell was voltage-clamped at $-70 \mathrm{mV}$ in artificial endolymph. At the relatively high oscillation frequency of $\sim 100 \mathrm{~Hz}$, the bundle did not display distinct slow and fast phases of movement. $B$, The application of saturating mechanical stimuli defined the range of open probabilities during spontaneous bundle oscillation. Bundle movements were recorded in the absence of stimulation and during positive and negative offsets that were large enough to saturate the mechanoelectrical transduction process (top records). The corresponding records of transduction current (bottom records) demonstrate that the large stimuli completely closed or opened the transduction channels, thereby abolishing oscillation. The transduction current in the absence of stimulation corresponded to open probabilities ranging from 0.13 to 0.70 . The base of the stimulus fiber, whose stiffness was $80 \mu \mathrm{N} \cdot \mathrm{m}^{-1}$, was displaced by $\pm 1000 \mathrm{~nm}$ to produce the saturating deflections.

\section{Effect of gentamicin on spontaneous oscillation}

An oscillatory hair bundle evinces a peculiar mechanical feature: its displacement-force relation, obtained by measuring the external force required to move the bundle through various distances, displays a region of negative stiffness (Martin et al., 2000). According to the gating-spring model of mechanoelectrical transduction (Corey and Hudspeth, 1983) (for review, see Markin and Hudspeth, 1995; Hudspeth et al., 2000), direct mechanical gating of transduction channels is expected to reduce the stiffness of a bundle over a limited range of positions (Howard and Hudspeth, 1988). For suitable values of the parameters of the model, this gating compliance can be great enough to dominate the other elastic components of the bundle and to render the stiffness of the bundle negative (Denk et al., 1992) (for review, see Markin and Hudspeth, 1995). Aminoglycoside antibiotics are known to block transduction channels (Kroese et al., 1989). By preventing channel gating, these drugs abolish gating compliance (Howard and Hudspeth, 1988) and should thus eliminate the negative stiffness of spontaneously oscillating bundles.

A spontaneously active hair bundle characteristically displayed a region of negative stiffness encompassing a displacement range of $\sim 20 \mathrm{~nm}$ (Fig. $4 A$ ). When the solution bathing the apical hair cell surface was replaced by artificial endolymph containing $60 \mu \mathrm{M}$ gentamicin, the bundle instead behaved as a Hookean spring throughout the range of deflections explored. The region of negative stiffness of the hair bundle was restored by exchanging the bath with gentamicin-free endolymph.

Active mechanical biasing of a hair bundle into its unstable region of negative stiffness can explain spontaneous oscillations (Martin et al., 2000). By eliminating negative stiffness, aminoglycosides would be expected to remove one of the conditions necessary for spontaneous oscillation. On iontophoretic application of gentamicin near the top of an oscillatory hair bundle, we found that the movements reversibly disappeared (Fig. 4B). Gentamicin arrested the hair bundle in a positive position, where most transduction channels are likely to be open (Fig. 3). This observation thus confirms the previous inference that gentamicin
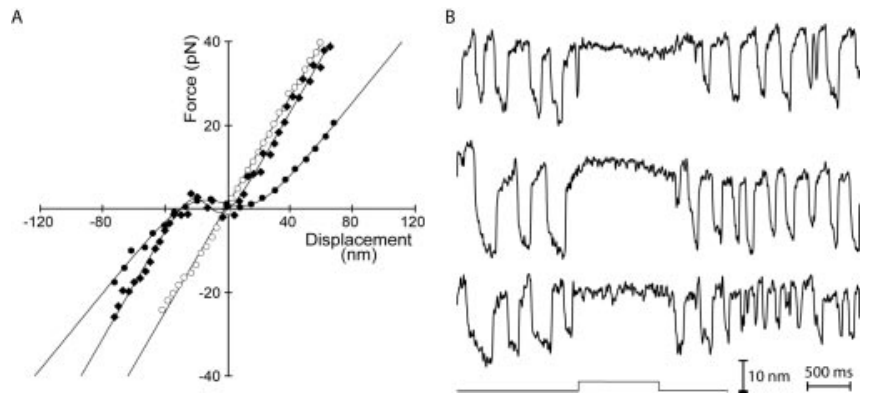

Figure 4. The effect of transduction channel blockage by the aminoglycoside antibiotic gentamicin. A, An oscillatory hair bundle initially displayed a region of negative stiffness in the displacement-force relation measured by displacement clamping (filled circles). When the solution bathing the hair bundle was replaced by artificial endolymph containing $60 \mu \mathrm{m}$ gentamicin, the region of negative stiffness vanished; the displacement-force relation became linear throughout the range of deflections explored (open circles). This effect was reversible in that negative stiffness was restored by returning gentamicin-free endolymph to the bath (diamonds). The fiber was detached from the tip of the bundle to allow successive bath exchanges. $B$, During each of three iontophoretic applications of gentamicin to the same hair bundle, the spontaneous oscillation vanished transiently. Because gentamicin blocks transduction channels in the open position, the bundle initially moved in the positive direction. When the drug encountered a bundle that was lurching in the negative direction, the bundle reversed abruptly and moved in the positive direction (top record). In contrast, very little positive motion resulted from applying the drug when the hair bundle was on the verge of jumping in the negative direction (center record). When the iontophoretic current was small enough, the hair bundle ceased oscillating but displayed rapid, noisy bundle movements. This noisy motion likely corresponded to channel clatter as the gentamicin molecules alternately blocked and unblocked the channels. The holding current was $-0.2 \mathrm{nA}$; the expulsion currents were $+2 \mathrm{nA}$ for the top two traces and $+1 \mathrm{nA}$ for the bottom trace. The 1 sec iontophoretic pulse is indicated below the experimental records.

blocks transduction channels in an open state (Denk et al., 1992; Jaramillo and Hudspeth, 1993). By blocking $\mathrm{Ca}^{2+}$ entry through open transduction channels, gentamicin should also interfere indirectly with the myosin-based molecular motors that effect adaptation to sustained stimuli (Eatock et al., 1987; Hacohen et al., 1989). After the initial blockage, a hair bundle often moved slowly in the negative direction, a phenomenon attributable to mechanical adaptation when $\mathrm{Ca}^{2+}$ entry was interrupted (Denk et al., 1992; Jaramillo and Hudspeth, 1993).

\section{Effect of pharmacological agents on spontaneous oscillation}

If spontaneous hair bundle oscillation involves the shape of the displacement-force relation of the bundle and the activity of adaptation motors, drugs that affect either would be expected to influence oscillation. Substances that interfere with the cAMP second messenger pathway evoke a shift of the transduction current-displacement curve (Ricci and Fettiplace, 1997; Géléoc and Corey, 2001) and are therefore suitable reagents with which to perturb oscillation. A wealth of information suggests that the molecular motors responsible for adaptation of the mechanoelectrical-transduction process are based on myosin molecules (for review, see Hudspeth and Gillespie, 1994; Gillespie and Corey, 1997; Eatock, 2000; Holt and Corey, 2000). Substances that interfere with force production by myosin would thus be expected to affect oscillation. An example is butanedione monoxime, which places myosin II molecules in a weakly bound state (Herrmann et al., 1992; Seow et al., 1997; Tesi et al., 2002). Although the effect of this substance on other myosin isozymes remains uncertain (Cramer and Mitchison, 1995; Ostap, 2002; Titus, 2003), butanedione monoxime lowers the open probability of transduction channels in hair cells (Wu et al., 1999) and may therefore affect adaptation motors. 


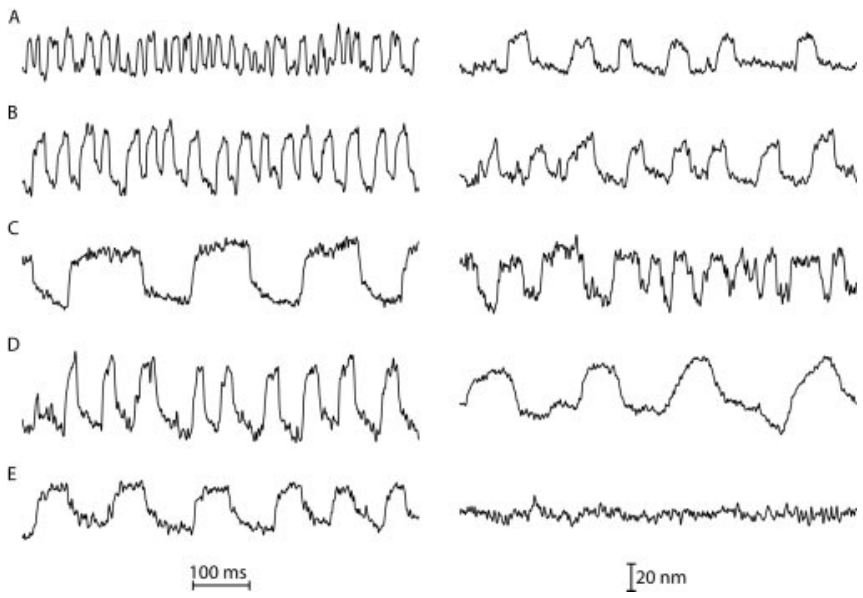

Figure 5. Effects of pharmacological agents on spontaneous hair bundle oscillation. In each instance, a control record is shown at the left, and a record in the presence of the drug is shown at the right; the corresponding recovery record is not illustrated. $A$, Forskolin lowered the frequency of spontaneous oscillation to one-third, from $33 \pm 17$ to $9 \pm 4 \mathrm{~Hz}$. The rms magnitude of the oscillation was relatively unaffected, falling from 11 to $10 \mathrm{~nm}$. When the drug was removed, the frequency recovered to $24 \pm 7 \mathrm{~Hz}$ with a magnitude of $9 \mathrm{~nm} . B, \mathrm{In}$ the presence of isobutyl methylxanthine, the frequency of an oscillation fell from $23 \pm 4$ to $10 \pm 3 \mathrm{~Hz}$; the magnitude declined from 16 to $11 \mathrm{~nm}$. C, Rp-adenosine 3',5'-cyclic monophosphorothioate increased the oscillation frequency from $5 \pm 2$ to $10 \pm 8 \mathrm{~Hz}$, whereas the magnitude of oscillation declined from 18 to $14 \mathrm{~nm}$. Restoring the control solution restored the frequency to $4 \pm 3 \mathrm{~Hz}$ with a magnitude of $17 \mathrm{~nm}$. D, The spontaneous oscillation of a hair bundle exposed to okadaic acid declined in frequency from $13 \pm 3$ to $5 \pm 2 \mathrm{~Hz}$; the magnitude fell from 20 to 16 $\mathrm{nm}$. During recovery, the oscillation frequency rose to $12 \pm 4 \mathrm{~Hz}$ with a magnitude of $7 \mathrm{~nm}$. $E$, Oscillation at $7 \pm 3 \mathrm{~Hz}$ with a magnitude of $13 \mathrm{~nm}$ was abolished by butanedione monoxime. All experiments were conducted with artificial endolymph.

Used at a concentration of $100 \mu \mathrm{M}$, forskolin, an activator of adenylate cyclase, consistently lowered the oscillation frequency in each of the four hair cells examined (Fig. 5A). Sp-adenosine $3^{\prime}, 5^{\prime}$-cyclic monophosphorothioate (Sp-cAMPS; $500 \mu \mathrm{M}$ ) and 8-bromo-cAMP (8-Br-cAMP; $100 \mu \mathrm{M})$, membrane-permeant analogs of CAMP that activate CAMP-dependent protein kinases, had similar effects in one and two cells, respectively (data not shown). 3-Isobutyl 1-methylxanthine (IBMX; $500 \mu \mathrm{M}$ ), an inhibitor of cAMP phosphodiesterases, also reduced the frequency of oscillation in each of the two cells studied (Fig. 5B). Rp-cAMPS $(500 \mu \mathrm{M})$, a membrane-permeant inhibitor of cAMP-dependent protein kinases, had the opposite effect in each of three hair cells: in the presence of the drug, the oscillation frequency increased appreciably (Fig. 5C). Finally, okadaic acid, an inhibitor of some protein phosphatases, slowed oscillation in both of the cells exposed to the drug at a concentration of $5 \mu \mathrm{M}$ (Fig. 5D). As expected, the myosin inhibitor butanedione monoxime (10 $\mathrm{mM})$ suppressed oscillation altogether in all four cells tested (Fig. 5E). In the many instances in which we were able to record bundle movements after control endolymph solution had been restored, we found that the oscillation frequencies returned to nearly their initial values.

Because each drug was applied by changing the solution contained in the upper compartment of the recording chamber, it was necessary to detach the stimulus fiber to prevent disruption of the recorded hair bundle by turbulence. This procedure might have affected an oscillation by damaging the bundle, offsetting its position, or affecting the strength or exact site of coupling between the fiber and bundle. However, although drugs other than butanedione monoxime could change the frequency of an oscillation by as much as threefold, the magnitude of oscillation dur- ing treatment remained within $30 \%$ of the control value. If this magnitude is determined by the shape of the displacement-force relation of the bundle (Martin at al, 2000), these observations suggest that hair bundles primarily retained their mechanical integrity throughout the experiment. In the cases of forskolin, 3-isobutyl 1-methylxanthine, and okadaic acid, the oscillation became slower and smaller on drug application. Because simply detaching and reattaching the fiber never produced these effects, the observed changes may safely be ascribed to the effects of the various drugs on the oscillation motor. Finally, to ensure that a bundle was not significantly offset after solution changes, we subjected most hair bundles to a range of static offsets both under control conditions and during drug exposure and compared the frequency ranges of the consequent oscillations. These control experiments confirmed in each instance that the effects of the drugs on oscillation frequency were legitimate.

\section{Effect of $\mathrm{Ca}^{2+}$ on spontaneous oscillation}

$\mathrm{Ca}^{2+}$ mediates both of the processes proposed to power mechanical amplification by hair bundles, activity of the adaptation motor (Eatock et al., 1987; Hacohen et al., 1989) (for review, see Hudspeth and Gillespie, 1994; Gillespie and Corey, 1997; Eatock, 2000; Holt and Corey, 2000) and rapid transduction channel reclosure (Howard and Hudspeth, 1988; Crawford et al., 1991; Benser et al., 1996; Ricci et al., 2000, 2002) (for review, see Hudspeth et al., 2000; Fettiplace et al., 2001). $\mathrm{Ca}^{2+}$ also reversibly affects the stiffness of a hair bundle (Marquis and Hudspeth, 1997) and the open probability of transduction channels at rest (Corey and Hudspeth, 1983; Hacohen et al., 1989). Finally, $\mathrm{Ca}^{2+}$ modulates the frequency of spontaneous otoacoustic emissions (Manley and Kirk, 2002). We therefore tested the effects of different extracellular $\mathrm{Ca}^{2+}$ concentrations on spontaneous hair bundle motion.

Varying the $\mathrm{Ca}^{2+}$ concentration by exchange of the solution bathing the apical surface of the saccular macula produced systematic changes in spontaneous oscillation. Raising the $\mathrm{Ca}^{2+}$ concentration from the control value of $250 \mu \mathrm{M}$ resulted in an increase in frequency and a decrease in amplitude of the oscillation of the bundle, whereas reducing the concentration had the opposite effect (data not shown). When the $\mathrm{Ca}^{2+}$ concentration exceeded $\sim 1 \mathrm{~mm}$, or when it fell below $\sim 100 \mu \mathrm{M}$, the oscillations disappeared. This effect was reversible, however, because reimposing a $\mathrm{Ca}^{2+}$ concentration near $250 \mu \mathrm{M}$ restored well defined bundle oscillations.

We performed additional experiments in which we used iontophoresis to rapidly raise or lower the $\mathrm{Ca}^{2+}$ concentration near the stereociliary tips while keeping the glass fiber attached to the kinociliary bulb. Transiently elevating the concentration with a $\mathrm{Ca}^{2+}$-containing electrode had three consistent and reversible effects: a hair bundle displayed a net movement in the negative direction; the amplitude of oscillation declined; and the frequency of oscillation increased (Fig. 6A). For small to moderate levels of iontophoresis, it was noteworthy that the increase in oscillation frequency involved principally a shortening of the slow component of movement in the positive direction. For a given bundle, the fastest oscillation that we could elicit by $\mathrm{Ca}^{2+}$ iontophoresis occurred at approximately twice the frequency of the control movement. The oscillation amplitude was not as strongly affected, decreasing by $\sim 20 \%$.

The greatest increases in $\mathrm{Ca}^{2+}$ concentration attained by iontophoresis suppressed rhythmic hair bundle activity (Fig. 6B). However, erratic, rapid movements lasting no more than 1-2 msec persisted. Because these spikes were distinct from the back- 
A
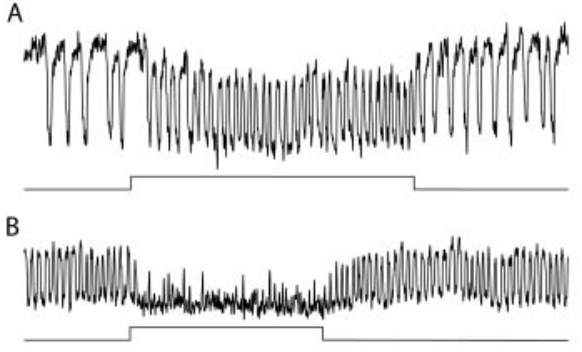

C

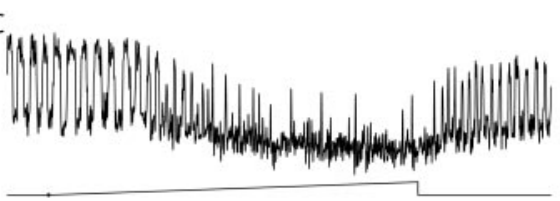

$\mathrm{D}$

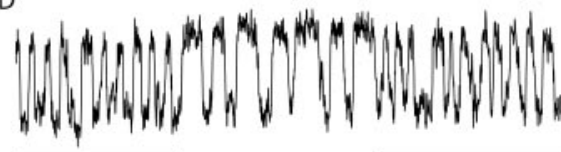

$\mathrm{E}$

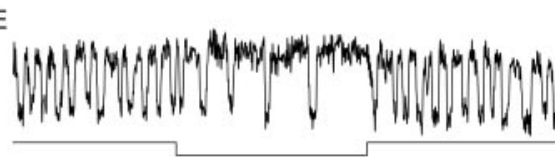

$\mathrm{F}$

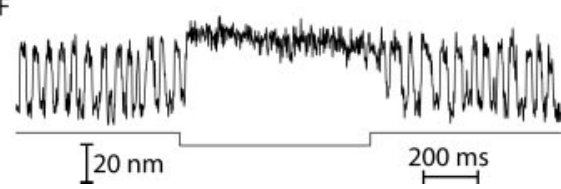

Figure 6. Effect of extracellular $\mathrm{Ca}^{2+}$ concentration on spontaneous hair bundle oscillation. $A$, When a spontaneously oscillating hair bundle was exposed to the $\mathrm{Ca}^{2+}$ expelled from an iontophoretic pipette, the increased $\mathrm{Ca}^{2+}$ concentration offset the bundle by $-7 \mathrm{~nm}$ and decreased the rms magnitude of the movement from $18 \mathrm{to} 16 \mathrm{~nm}$. The frequency of oscillation also rose from $17 \pm 8$ to $34 \pm 6 \mathrm{~Hz}$, primarily by shortening of the positive phase of motion. The 1 seciontophoretic pulse is indicated below the experimental record in this and the subsequent records. The holding current was $-15 \mathrm{nA}$, and the expulsion current was +10 $\mathrm{nA} . \mathrm{B}$, Although the largest $\mathrm{Ca}^{2+}$ ejections suppressed rhythmic hair bundle activity, fast, erratic movements remained. These spikes lasted no more than a few milliseconds and were characterized by peak-to-peak magnitudes up to $80 \%$ those of the unperturbed bundle oscillation. Before application of the 0.7 sec iontophoretic pulse, the spontaneous oscillation of this bundle was characterized by an rms magnitude of $12 \mathrm{~nm}$ and a frequency of $42 \pm 6 \mathrm{~Hz}$. The pulse caused a static bundle deflection of -4 $\mathrm{nm}$. The holding current was $-15 \mathrm{nA}$, and the expulsion current was $+30 \mathrm{nA} . \mathrm{C}_{1} \mathrm{Ca}^{2+}$ expelled by a ramp of iontophoretic current initially accelerated and eventually suppressed spontaneous bundle oscillation. Fast, spiky movements of relatively large magnitudes remained. The 1.25 sec linear ramp of iontophoretic current commenced at the dot. The holding current was $-15 \mathrm{nA}$, and the maximal expulsion current was $+60 \mathrm{nA}$. The greatest hair bundle offset induced by $\mathrm{Ca}^{2+}$ iontophoresis was $-18 \mathrm{~nm}$. D, An 0.7 -sec iontophoretic pulse of ATP decreased the local $\mathrm{Ca}^{2+}$ concentration around a hair bundle, causing a net movement of +5 $\mathrm{nm}$ and prolonging the positive phase of oscillation. The spontaneous oscillation of the bundle increased slightly in rms magnitude, from 18 to $20 \mathrm{~nm}$, whereas its frequency fell nearly by half, from $17 \pm 4$ to $10 \pm 3 \mathrm{~Hz}$. The holding current was $+5 \mathrm{nA}$, and the maximal expulsion current was $-15 \mathrm{nA}$. E, A greater reduction of the $\mathrm{Ca}^{2+}$ concentration, effected by the iontophoretic application of an $0.7 \mathrm{sec}$ ATP pulse, further prolonged the slow component of positive bundle movement but left the negative phase unchanged. The holding current was $+5 \mathrm{nA}$, and the expulsion current was $-20 \mathrm{nA}$. F, Even greater reduction of the $\mathrm{Ca}^{2+}$ concentration suppressed the oscillation, originally $14 \mathrm{~nm}$ in rms magnitude and $21 \pm 4 \mathrm{~Hz}$ in frequency, and caused a bundle offset of $+6.5 \mathrm{~nm}$. The noisy displacement fluctuations that persisted had an rms magnitude of $7 \mathrm{~nm}$. The holding current was $+0.5 \mathrm{nA}$, and the expulsion current was $-40 \mathrm{nA}$.

ground noise apparent under control conditions during the slow components of oscillation, they probably represented residual active bundle motion. At the conclusion of the iontophoretic pulse, the oscillation resumed progressively, further demonstrating the relation among movement amplitude, frequency, and the duration of the positive phase of bundle movement. The use of iontophoretic pulses of varying intensity or the application of a ramp of iontophoretic current disclosed that a progressive increase in $\mathrm{Ca}^{2+}$ concentration evokes graded effects (Fig. 6C).

We were also able to lower transiently the local $\mathrm{Ca}^{2+}$ concentration around a hair bundle by iontophoresis of a chelator. Because carboxylate $\mathrm{Ca}^{2+}$ chelators damage the transduction process by breaking tip links (Assad et al., 1991; Crawford et al., 1991; Marquis and Hudspeth, 1997), we elected to use ATP to sequester $\mathrm{Ca}^{2+}$ (for review, see Fabiato and Fabiato, 1979). The effects of applying this nucleotide were opposite those of $\mathrm{Ca}^{2+}$ iontophoresis. For low to modest levels of iontophoresis, the bundle displayed an offset in the positive direction and a graded slowing of spontaneous oscillations dominated by protraction of their slow component of positive motion (Fig. 6D,E). The ATP ejected by stronger iontophoretic currents entirely suppressed oscillations, producing a significant bundle excursion in the positive direction (Fig. 6F).
Effect of bundle position on spontaneous oscillation

By applying step displacements at the base of a flexible stimulus fiber, we analyzed the effect on a spontaneously oscillating hair bundle of deflecting its top by distances up to $\pm 200 \mathrm{~nm}$. Large offsets completely but reversibly suppressed the oscillation (data not shown). For bundle displacements smaller than $\sim 150 \mathrm{~nm}$ in either direction, however, a bundle remained quiescent only transiently (Fig. 7). During this period, the hair bundle relaxed slowly in the direction of the stimulus with a time course characteristic of mechanical adaptation (Eatock et al., 1987; Hacohen et al., 1989). After the bundle position had attained a plateau and adaptation had presumably concluded, the oscillation eventually resumed.

The recovery of oscillation during a protracted displacement could be abrupt for small bundle offsets but was graded for larger ones. In the latter case, oscillation grew progressively over the course of a few cycles from zero amplitude to a steady-state level and correspondingly decreased its frequency. The recovery was not complete, however, in that the oscillation was consistently faster than at rest when the bundle was offset in the positive direction and slower when it was displaced in the negative direction. In contradistinction to the effect of changes in $\mathrm{Ca}^{2+}$ concentration near the stereociliary tips, bundle offset affected primarily the slow component of negative movement. The symmetry of oscillation was modified in such a way that a bundle displayed spiky movements in one direction when it was offset in the other.

\section{Effect of mechanical load on spontaneous oscillation}

When attached to the flexible glass fibers used in this study, most hair bundles oscillated at frequencies near $10 \mathrm{~Hz}$. These frequencies lie near the bottom of the range of $5-150 \mathrm{~Hz}$ that is characteristic of saccular nerve fibers (Koyama et al., 1982; Yu et al., 1991) and presumably of the corresponding hair cells. Although several aspects of in vitro recording might have perturbed the oscillation frequency, one condition whose effect could readily be tested was the elastic load against which the hair bundle operated.

While recording spontaneous bundle oscillations, we used varying degrees of negative feedback, or partial displacement clamping, to increase the effective stiffness of the stimulus fiber attached to a bundle. When the stiffness of the fiber rose, the magnitude of the oscillation of a bundle characteristically declined as the frequency of spontaneous oscillation increased (Fig. $8 A$ ). A sufficiently great increase in the effective stiffness of the stimulus fiber suppressed well defined bundle oscillations altogether (Fig. $8 \mathrm{~B}$ ).

The effect of mechanical load on the frequency and amplitude of spontaneous hair bundle oscillation bears on the status of unstimulated bundles in vivo. Like those in most acousticolateralis organs, a hair bundle of the bullfrog's sacculus is normally at- 


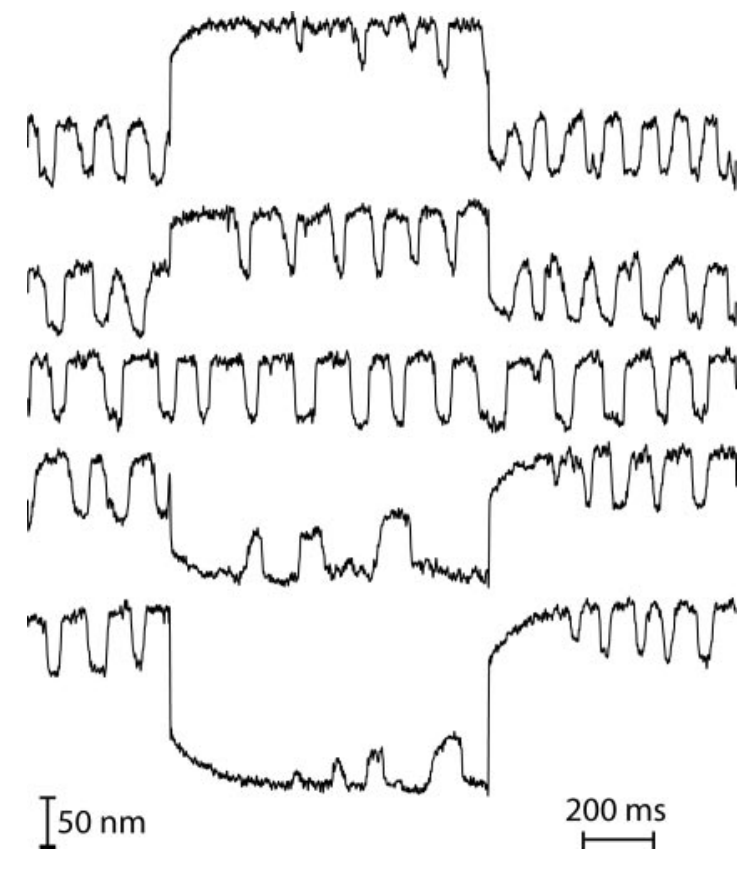

Figure 7. Effect of offset on spontaneous hair bundle oscillation. The center record demonstrates an unperturbed bundle oscillation at a frequency of $7 \pm 3 \mathrm{~Hz}$ with an rms magnitude of $27 \mathrm{~nm}$. From top to bottom, the remaining records show the effect of offsetting the tip of the bundle by $+140,+85,-95$, and $-160 \mathrm{~nm}$. In each instance, after having been suppressed for a period of adaptation, the oscillation resumed. After the largest offsets, the magnitude of oscillation grew progressively from zero. Positive offsets shortened the negative phase of bundle movement, whereas negative offsets had the opposite effect. Offsets thus perturbed the symmetry of the oscillation. The stiffness of the fiber was $130 \mu \mathrm{N} \cdot \mathrm{m}^{-1}$.

tached to an accessory structure. In the intact ear, the bulbous tip of the single kinocilium in the bundle is linked by numerous filaments to the compact layer of the otolithic membrane (Hillman and Lewis, 1971; Jacobs and Hudspeth, 1990; Kachar et al., 1990). The polycrystalline otoconia that surmount this structure constitute an inertial mass whose movement relative to the skull signals acceleration. Although the mechanical properties of the otolithic membrane are complex (Benser et al., 1993), the structure exhibits a steady-state stiffness of $1400 \pm 800 \mu \mathrm{N} \cdot \mathrm{m}^{-1}$ for each of the $\sim 2500$ attached hair bundles. The present results suggest that the stiffness of the otolithic membrane is comparable with the minimal load required to suppress spontaneous oscillation.

\section{Role of the kinocilium in spontaneous oscillation}

In addition to the clustered stereocilia that mediate mechanoelectrical transduction (Hudspeth and Jacobs, 1979), every hair bundle, at least during its development, includes a single kinocilium. Because it contains an axoneme, or $9+2$ array of microtubules adorned with dynein motor molecules, a kinocilum is capable of performing mechanical work. A kinocilium can oscillate spontaneously (Bowen, 1931) and can move in response to electrical stimulation (Rüsch and Thurm, 1990). Because this organelle has been suggested to contain the motor molecules responsible for hair bundle oscillation (Camalet et al., 1999, 2000), we wished to determine its role in the process.

A kinocilium may be detached from the stereociliary cluster by microdissection with the tip of a microelectrode (Hudspeth and Jacobs, 1979). We selected hair bundles that displayed robust spontaneous oscillations in artificial endolymph solution. After the kinocilium had been detached from each of five such bundles, all continued their active movements (Fig. 9). Even flattening the kinocilium against the apical surface of the hair cell and holding it pointed away from the stereociliary cluster with the dissecting electrode did not arrest spontaneous movements. In most instances, the magnitude of the oscillation increased slightly after dissection. This response might indicate that a kinocilium imposes a load on the stereociliary cluster (Crawford and Fettiplace, 1985). The change after dissection might alternatively stem from repositioning of the stimulus fiber at the top of a bundle, slightly farther from the apical surface of the cell than the control point of attachment at the kinociliary bulb.

\section{Model for spontaneous hair bundle oscillation}

To ascertain whether our understanding of the principal features of spontaneous hair bundle oscillation accords with the present experimental findings, we developed a model for oscillations and tested its performance in simulations of several experimental conditions. More specifically, we assembled equations to represent hair bundle mechanics, mechanoelectrical transduction and the flow of ionic current, adaptation of the transduction process, and $\mathrm{Ca}^{2+}$-dependent channel reclosure. We did not include the effects of noise in the model. These equations, their origins and justifications, and other features of the model are described in the Appendix.

The model yields simulated oscillations resembling those observed experimentally. In particular, adjustment of parameter values within a range that accords with other measurements readily produces oscillations of frequencies extending throughout and beyond the observed range of $5-50 \mathrm{~Hz}$ and of peak-topeak magnitudes up to $70 \mathrm{~nm}$. The oscillation waveforms resemble those of actual bundle movements (Fig. 10A,B). Each phase of the slower oscillations is bipartite, with a rapid initial component followed by a slow relaxation. As for actual oscillations, the slow components may be approximately exponential, essentially flat, or even nonmonotonic.

Changing the extracellular $\mathrm{Ca}^{2+}$ concentration affects simulated oscillations as it does actual bundle movements. In particular, an abrupt increase in $\mathrm{Ca}^{2+}$ concentration, similar to that during iontophoretic application of the ion, accelerates oscillations by shortening the slow component of positive motion and reduces their magnitude (Fig. 10C). A comparable concentration decrease, which mimics the effect of iontophoretic ejection of a $\mathrm{Ca}^{2+}$ chelator, slows oscillations by prolonging the slow component of positive movement and augments their size (Fig. 10D).

The formulation of the model for the mechanism of $\mathrm{Ca}^{2+}$ dependent channel reclosure was meant to encompass the experimental observation that the amplitude of oscillation changes in response to alterations of the extracellular $\mathrm{Ca}^{2+}$ concentration. If each cycle of oscillation represents a trajectory around the displacement-response relation (Martin et al., 2000), its amplitude can be changed only by adjusting the shape of the relation. In the present model, $\mathrm{Ca}^{2+}$ entry into the stereociliary cytoplasm relaxes a component of the gating spring, thus reducing the magnitude of negative stiffness and shortening the oscillatory trajectory. The response of the model to simulated $\mathrm{Ca}^{2+}$ exposure captures this aspect of the experimental result.

The model also recapitulates the effects of increasing the mechanical load on a hair bundle. As the stiffness of the fictive stimulus fiber increases, oscillation becomes faster and smaller (Fig. $10 E$ ) until it is wholly suppressed.

Modeling readily simulates the effects of pharmacological reagents on spontaneous hair bundle oscillation. Reducing the rate of adaptation motor climbing lowers the frequency of oscillation 

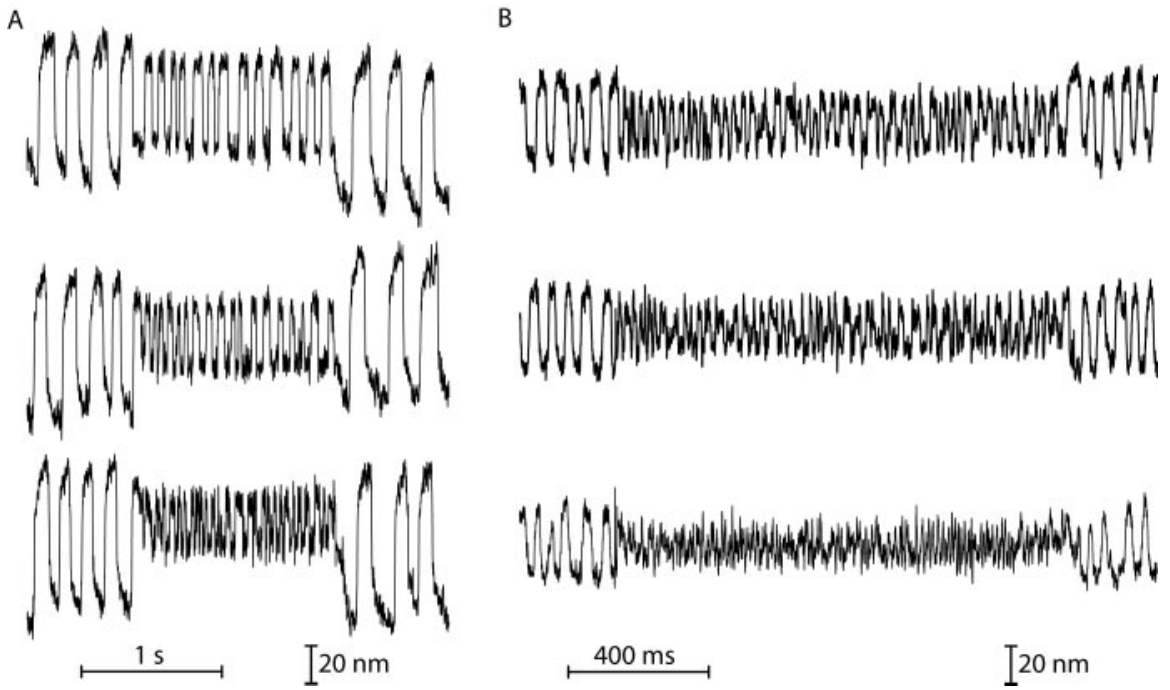

Figure 8. Effect of mechanical load on hair bundle oscillation. As a bundle oscillated spontaneously, partial displacement clamping was abruptly activated during the 1.2 sec epoch at the center of each record. Because the movement of the base of the fiber opposed that of the hair bundle, activating the clamp system increased the effective impedance of the fiber above its actual value of $152 \mu \mathrm{N} \cdot \mathrm{m}^{-1}$. A, The hair bundle oscillated spontaneously at $5 \mathrm{~Hz}$ with an rms magnitude of $33 \mathrm{~nm}$. The effective stiffness of the fiber during partial displacement clamping increased to $260 \mu \mathrm{N} \cdot \mathrm{m}^{-1}$ (top record), then to $490 \mu \mathrm{N} \cdot \mathrm{m}^{-1}$ (middle record), and finally to $690 \mu \mathrm{N} \cdot \mathrm{m}^{-1}$ (bottom record). The increasing load raised the frequency of oscillation successively to $9 \pm 3$, then to $12 \pm 4$, and finally to $18 \pm 10 \mathrm{~Hz}$. The rms magnitude of oscillation correspondingly decreased to 22 , then to 14 , and finally to $12 \mathrm{~nm}$. $B$, Another hair bundle, contacted by the same fiber as in A, oscillated spontaneously at $21 \mathrm{~Hz}$ with an rms magnitude of $18 \mathrm{~nm}$. During partial displacement clamping, the effective stiffness of the fiber rose to $750 \mu \mathrm{N} \cdot \mathrm{m}^{-1}$ (top record), then to $1070 \mu \mathrm{N} \cdot \mathrm{m}^{-1}$ (middle record), and finally to $1390 \mu \mathrm{N} \cdot \mathrm{m}^{-1}$ (bottom record). The oscillation frequency increased to $34 \pm 9$ and then to $41 \pm 20 \mathrm{~Hz}$, whereas the rms magnitude decreased to 10 and then to $9 \mathrm{~nm}$. The greatest effective stiffness of the fiber suppressed well defined hair bundle oscillations, leaving noisy bundle movements with an rms magnitude of $7 \mathrm{~nm}$.

by prolonging the negative phase of movement. Such a change would occur in response to substances that promote protein phosphorylation, such as forskolin, IBMX, 8-Br-cAMP, SpcAMP, and okadaic acid. Increasing the climbing rate of the motor recapitulates the effect of Rp-cAMP, which presumably reduces phosphorylation, by accelerating oscillation. Not surprisingly, eliminating or greatly reducing the motility of a myosin-based motor, as might be effected by butanedione monoxime, suppresses oscillations (data not shown).

Modeling affords an opportunity to gain insight into complex physiological processes by examining the behavior of parameters whose values cannot be measured experimentally. For an oscillation $78 \mathrm{~nm}$ in peak-to-peak magnitude (Fig. 11A), the model suggests that the $\mathrm{Ca}^{2+}$ concentration rises as high as $10-20 \mu \mathrm{M}$ at the adaptation motor and reclosure element. In the same instance, the total excursion of the insertion of a gating spring as a result of adaptation is predicted to be $\sim 7 \mathrm{~nm}$. The model implies that the mechanical twitch observed in standard saline solution when a bundle moves abruptly in the positive direction (Howard and Hudspeth, 1987a, 1988; Benser et al., 1996) stems from the rapid, $\mathrm{Ca}^{2+}$-dependent relaxation of an intracellular component of the gating spring whose softening fosters channel closure. In the steady state, the displacement-force relation and displacement-open probability relation of a bundle are symmetrical with respect to the bundle position at which half the channels are open (Fig. 11). In the case of an oscillating bundle, however, the model predicts an asymmetry between the positive and negative phases of bundle movement and of the corresponding trajectory of channel open probability. When the bundle moves in the positive direction, the opening of transduction channels admits $\mathrm{Ca}^{2+}$, which binds to the reclosure element and lowers the stiffness of the bundle. During the negative phase of motion, however, $\mathrm{Ca}^{2+}$ entry diminishes and the bundle becomes stiffer. As a result, the displacement-force and displacement-open probability relations of the bundle continuously adjust their shapes during the oscillation, causing the trajectories of the bundle in the two directions to display hysteresis. This effect potentially explains the measured asymmetry of the open probability oscillation (Fig. 3).

A few features of the experimental results are not represented in the simulations. In response to an increased or decreased $\mathrm{Ca}^{2+}$ concentration, for example, hair bundles display gradual changes on a time scale of hundreds of milliseconds (Fig. 6). These responses may reflect stereociliary $\mathrm{Ca}^{2+}$ homeostasis (Lumpkin and Hudspeth, 1998; Ricci et al., 1998; Yamoah et al., 1998), which has been omitted from the model. Perhaps for the same reason, the model cannot reproduce the slow, progressive recovery of oscillations after large bundle offsets (Fig. 7).

\section{Discussion}

In a simple model, only two ingredients are necessary to endow a hair bundle with the ability to oscillate spontaneously: a region of negative stiffness in the displacement-force relation of the bundle and a biasing element, such as the adaptation motor, that forces the bundle into this unstable region (Martin et al., 2000). The present results support this model by confirming several predictions based on it. In addition, they reveal that the negative stiffness of the hair bundle and the adaptation motor are both affected by external perturbations, suggesting potential regulatory mechanisms by which active hair bundle motility might optimize the response of a hair cell to mechanical stimulation.

\section{Relation of oscillation to transduction channel gating}

The negative stiffness of a hair bundle originates from gating compliance, a reduction in stiffness associated with the mechanical gating of transduction channels (Howard and Hudspeth, 1988) (for review, see Hudspeth et al., 2000). It therefore stands to reason that bundle oscillation is abolished by blockage of transduction channels with gentamicin, a procedure that arrests channel gating and thereby eliminates negative stiffness (Fig. 4).

Our electrical recordings also concur with theory by associating the positive phase of bundle movement with channel opening and the negative with closure. The results are consistent with the hypothesis that channel gating provides one of the forces that generate hair bundle motion.

The magnitude of oscillation depends on the trajectory that an active hair bundle executes with respect to its displacement-force relation (Fig. 11). In principle, the size of an oscillation depends on the magnitude of the gating compliance of a bundle relative to the combined stiffness of the other elastic components of the bundle and the load. Increasing the elastic load applied to the bundle would be anticipated to diminish the oscillations until it suppresses them altogether. Both the experimental result (Fig. 8) and the simulation (Fig. $10 \mathrm{E}$ ) accord with this expectation. Al- 
A
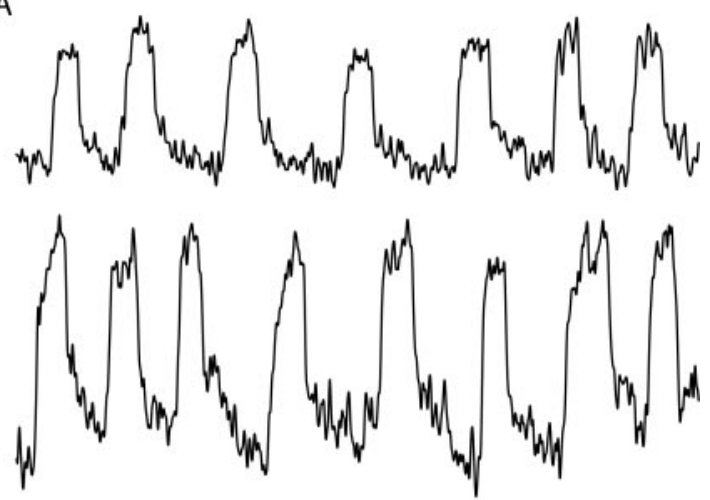

B
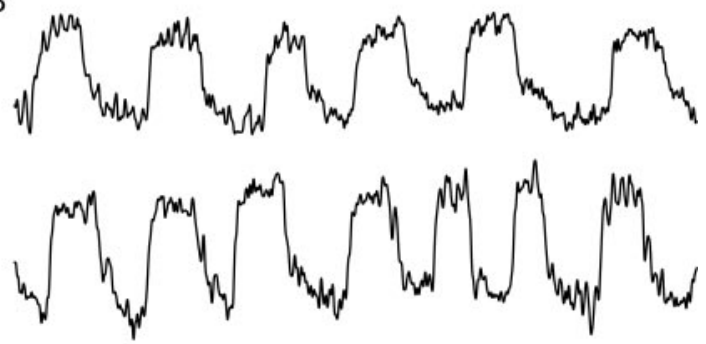

$\lceil 20 \mathrm{~nm}$

Figure 9. Persistence of spontaneous hair bundle oscillation after kinociliary detachment. $A$, A hair bundle initially displayed spontaneous oscillations at $10 \pm 6 \mathrm{~Hz}$ with a magnitude of 16 $\mathrm{nm}$ (top record). After the kinocilium had been disconnected from the contiguous stereocilia and flattened against the epithelial surface with a glass microelectrode, the bundle continued to oscillate at $11 \pm 4 \mathrm{~Hz}$ (bottom record). In this instance, the magnitude of oscillation increased to $26 \mathrm{~nm}$. B. Another hair bundle, which originally oscillated at $9 \pm 3 \mathrm{~Hz}$ with a magnitude of $12 \mathrm{~nm}$ (top record), survived microsurgery with oscillations at $10 \pm 4 \mathrm{~Hz}$ and 16 $n m$ in magnitude (bottom record).

ternatively, reduced gating compliance would flatten the displacement-force relation and yield smaller oscillations.

\section{Participation of myosin in oscillation}

Adaptation by the mechanoelectrical transduction process of the bullfrog's hair cells is mediated by myosin molecules, in particular myosin Ic (for review, see Hudspeth and Gillespie, 1994; Gillespie and Corey, 1997; Eatock, 2000). The success of the model at simulating most of the present results reinforces the previous inference (Martin et al., 2000) that the combination of adaptation motors and negative bundle stiffness underpins spontaneous hair bundle oscillation.

Phosphorylation of proteins associated with transduction channels, including the channels themselves, could explain the effects of drugs that interact with the cAMP signaling pathway. In particular, cAMP analogs and other substances that affect the activity of protein kinase $\mathrm{A}$, and the phosphorylation of its targets might influence myosin-based adaptation motors, whose activity contributes to setting the operating point of transduction (Hacohen et al., 1989). In many cells, $\mathrm{Ca}^{2+}$ interacts with calmodulin to activate adenylyl cyclase, producing cAMP that stimulates protein kinase A. This enzyme then phosphorylates the target proteins that constitute the effectors of the pathway. In the present instance, it is attractive to hypothesize that the operation of adaptation motors is impeded by the phosphorylation of myosin Ic at a consensus target site, such as serine 701 of the bullfrog's

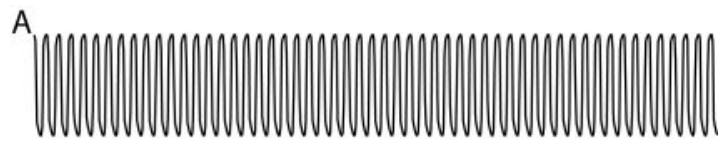

B
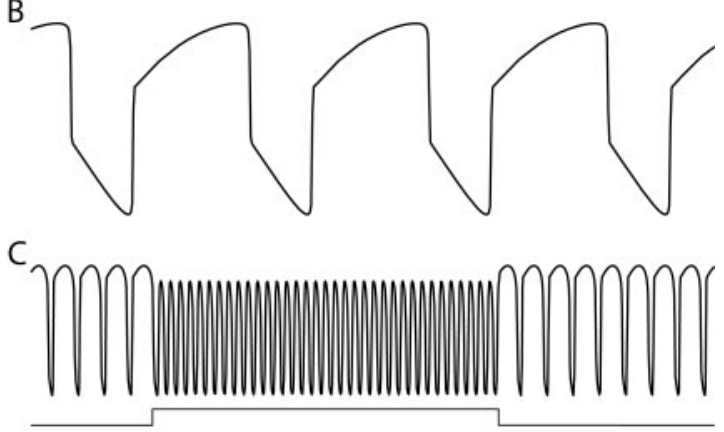

D

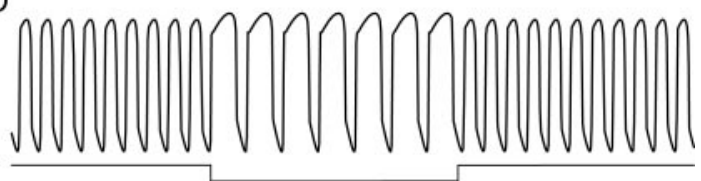

$\mathrm{E}$

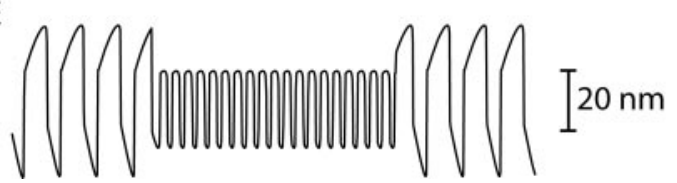

Figure 10. Simulations of spontaneous hair bundle oscillations and effects of experimental procedures. Each record was produced by the model described in Appendix, with most of the parameter values shown in Table 1. Record $D$ was produced with exactly the values in Table 1; the values that were altered for other records are provided in the captions below. All the records have a common distance scale, but the time scales vary so that each record may be compared with the corresponding experimental trace. Except when indicated, each record's the total length of each record is $2 \mathrm{sec}$. A, A high-frequency spontaneous oscillation produced by the model displays symmetry of its positive and negative phases (compare with Fig. $2 B$ ). $C_{\text {MAX }}=$ $0.31 \mu \mathrm{m} \cdot \mathrm{sec}^{-1} ; S_{\text {MAX }}=420 \mathrm{~km} \cdot \mathrm{sec}^{-1} \cdot \mathrm{N}^{-1} ; k_{\text {OFF, }}=50 \cdot 10^{3} \mathrm{sec}^{-1} ; k_{\text {OFF,RE }}=75 \cdot 10^{3}$ $\sec ^{-1} ; \Delta E^{\emptyset}=70 \mathrm{zJ}$; and $X_{S P}=272 \mathrm{~nm}$. $B$, Each phase of a large low-frequency modeled oscillation comprises a fast component followed by a slow movement in the same direction (compare with Fig. 2E). $d=9 \mathrm{~nm} ; C_{\text {MAX }}=0.15 \mu \mathrm{m} \cdot \mathrm{sec}^{-1} ; S_{\operatorname{MAX}}=390 \mathrm{~km} \cdot \mathrm{sec}^{-1} \cdot \mathrm{N}^{-1}$; $k_{\mathrm{ON}, \mathrm{M}}=1.1 \cdot 10^{9} \mathrm{sec}^{-1} \cdot \mathrm{M}^{-1} ; k_{\mathrm{OFF}, \mathrm{M}}=80 \cdot 10^{3} \mathrm{sec}^{-1} ; \kappa_{\mathrm{RE}, \mathrm{MAX}}=1200 \mu \mathrm{N} \cdot \mathrm{m}^{-1}$; $\kappa_{\mathrm{RE}, \mathrm{MIN}}=200 \mu \mathrm{N} \cdot \mathrm{m}^{-1} ; k_{\mathrm{OFF}, \mathrm{RE}}=75 \cdot 10^{3} \mathrm{sec}^{-1} ; \Delta E^{\emptyset}=65 \mathrm{z} ;$; and record length $=500$ msec. C, The response of the model to an elevation of the extracellular $\mathrm{Ca}^{2+}$ concentration was mimicked by evaluating the response to a $10 \mathrm{nA}$ rectangular pulse of iontophoretic current, indicated beneath the record, with a transfer number of 0.1 for $\mathrm{Ca}^{2+} . \mathrm{Ca}^{2+}$ accelerates the oscillations but renders them smaller (compare with Fig. $6 \mathrm{~A}$ ). $C_{\mathrm{MAX}}=0.22 \mu \mathrm{m} \cdot \mathrm{sec}^{-1}$; $S_{\mathrm{MAX}}=220 \mathrm{~km} \cdot \mathrm{sec}^{-1} \cdot \mathrm{N}^{-1} ; k_{0 \mathrm{FF}, \mathrm{M}}=50 \cdot 10^{3} \mathrm{sec}^{-1} ; \kappa_{\mathrm{RE}, \mathrm{MIN}}=200 \mu \mathrm{N} \cdot \mathrm{m}^{-1} ; \Delta E^{\varnothing}=54$ $\mathrm{Z}$; and $X_{\mathrm{SP}}=178 \mathrm{~nm}$. D, The response to iontophoretic application of a $\mathrm{Ca}^{2+}$ chelator, indicated below the trace, was modeled by reducing the extracellular $\mathrm{Ca}^{2+}$ concentration. The removal of $\mathrm{Ca}^{2+}$ slows oscillations and slightly augments their amplitude (compare with Fig. 6D). E, Modeling an increase in the load imposed by the stimulus fiber from 152 to $490 \mu \mathrm{N} \cdot \mathrm{m}^{-1}$ during the middle portion of the record produces smaller and faster oscillations (compare with Fig. $8 \mathrm{~A}$, middle record). $C_{\text {MAX }}=0.06 \mu \mathrm{m} \cdot \mathrm{sec}^{-1} ; S_{\text {MAX }}=110 \mathrm{~km} \cdot \mathrm{sec}^{-1} \cdot \mathrm{N}^{-1} ; k_{\text {OFF, M }}=80 \cdot 10^{3}$ $\mathrm{sec}^{-1} ; \kappa_{\mathrm{RE}, \mathrm{MIN}}=200 \mu \mathrm{N} \cdot \mathrm{m}^{-1} ; \mathrm{k}_{0 \mathrm{FF}, \mathrm{RE}}=75 \cdot 10^{3} \mathrm{sec}^{-1} ; \Delta E^{\emptyset}=68 \mathrm{zJ} ; X_{\mathrm{SP}}=251 \mathrm{~nm} ;$ and record length $=2.5 \mathrm{sec}$.

myosin Ic (Metcalf et al., 1994; Solc et al., 1994; G. Géléoc, P. Gillespie, and D. Corey, personal communication).

Butanedione monoxime blocks spontaneous hair bundle oscillation. Because this substance interferes with the ATPase cycle of myosin II (Herrmann et al., 1992; Seow et al., 1997; Tesi et al., 2002), this effect may reflect the arrest of myosin-based adaptation motors. This inference must be qualified, however, because the substance affects other physiological processes as well. $\mathrm{Bu}$ - 


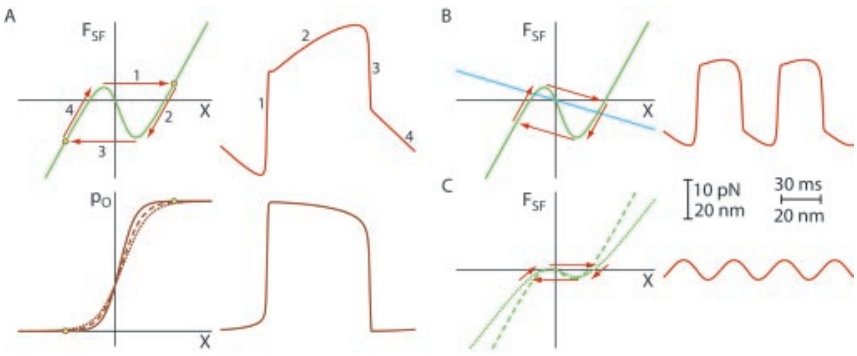

Figure 11. Model for spontaneous hair bundle oscillation driven by the adaptation motor. $A$, The displacement-force relation at the top left (green curve) shows the instantaneous stimulus fiber force $\left(F_{\mathrm{SF}}\right)$ necessary to hold the hair bundle at a given position $(X)$, as set by a displacement-clamp apparatus. This relation is specified by the steady-state solution of Equation 5 with $x_{\mathrm{A}}=0$. The region of negative stiffness corresponds to most of the range of bundle positions in which transduction channels are moving between their closed and open states, as revealed by the dependence of $p_{0}$ on bundle displacement represented by the continuous line at the bottom left. The adaptation motor strives to position the hair bundle near the middle of the displacement-force relation, in this instance at $p_{0}=0.35$. Because it is unstable in the region of negative slope stiffness, however, the hair bundle is destined to oscillate. The red arrows delineate the trajectory of bundle movements corresponding to the oscillation at the top right. Any perturbation that nudges the bundle into to the right part of the negative-stiffness region obliges the bundle to lurch in the positive direction (step 1). As shown in the plot of open probability against time at the bottom right, this movement raises the open probability of the transduction channel to $\sim 1$. Slipping adaptation then ensues, causing a slow component of movement (step 2) and lowering the open probability of the transduction channels to a value of $\sim 0.8$. When mechanical instability prompts another fast component of movement in the negative direction (step 3), the open probability of the channel falls to $\sim 0$. Climbing adaptation then raises the open probability to $\sim 0.1$ while completing a cycle of oscillation (step 4 ). Note that the plots of force and open probability against displacement represent steady-state relations with a fixed value for the gating spring stiffness, $1050 \mu \mathrm{N} \cdot \mathrm{m}^{-1}$, characteristic of an open probability of 0.35 . During the positive phase of each cycle of oscillation, however, the effect of $\mathrm{Ca}^{2+}$ entry on the reclosure element decreases the gating spring stiffness from a maximal value of $1143 \mu \mathrm{N} \cdot \mathrm{m}^{-1}$ to a minimum of $808 \mu \mathrm{N} \cdot \mathrm{m}^{-1}$. As a consequence and in agreement with the experimental results (Fig. 3), the simulated excursion of open probability in the time domain is asymmetrical. The displacement-force relation and oscillation correspond to the values of Table 1 but with $\mathrm{K}_{\mathrm{SF}}=0 \mu \mathrm{N} \cdot \mathrm{m}^{-1}$. The range of open probabilities from 0 to 1 is calibrated by the extremes of the steady-state relation of open probability to displacement. $B$, When the bundle is attached to a stimulus fiber of stiffness $\mathrm{K}_{\mathrm{SF}}=150 \mu \mathrm{N} \cdot \mathrm{m}^{-1}$, its oscillation follows a trajectory whose fast components parallel the load line of slope $-\mathrm{K}_{\mathrm{SF}}$ (blue line). The resultant bundle movement, which is smaller than that in $A$ and occurs at a greater frequency, corresponds to the values in Table 1 . The displacement-open probability relation in this instance is identical to that in $A$. C, By altering the shape of the displacement-force relation, $\mathrm{Ca}^{2+}$ also affects the magnitude, frequency, and waveform of spontaneous oscillation. Bundle movements become smaller and faster when the single-channel gating force, $z=\gamma \kappa_{\mathrm{GS}} d$, is decreased by a diminution in either the maximal stiffness of the reclosure element, here $\kappa_{\mathrm{RE}, \mathrm{MAX}}=860 \mu \mathrm{N} \cdot \mathrm{m}^{-1}$ (oscillation at right and dotted green curve at left), or the gating distance, here $d=5.2 \mathrm{~nm}$ (dashed green curve at left). Note that in the first case, both the static stiffness and maximum negative stiffness of the bundle are reduced, whereas in the second case, only the negative stiffness is affected (compare $B, C$ ). The remaining parameter values correspond to those in Table 1, again with $\mathrm{K}_{\mathrm{SF}}=0 \mu \mathrm{N} \cdot \mathrm{m}^{-1}$. The displacement-open probability relations for these circumstances are shown at the bottom left in $A$; the curve for diminished stiffness is dotted, and that for reduced gating distance is dashed. The identical vertical and horizontal distance calibrations apply to the abscissas of all graphs as well as to the simulated oscillations.

tanedione monoxime broadens the displacement-transduction current relation of a bundle ( $\mathrm{Wu}$ et al., 1999), suggesting that gating compliance is diminished, so the blockage of oscillation might reflect a decrease in the negative stiffness of the bundle. The compound can also block ion pumps (Tucker and Fettiplace, 1996) that might influence stereociliary $\mathrm{Ca}^{2+}$ homeostasis.

\section{Effects of $\mathrm{Ca}^{2+}$ on oscillation}

Altering the $\mathrm{Ca}^{2+}$ current that enters the stereociliary cytoplasm through transduction channels has an immediate effect on oscil- lation: $\mathrm{Ca}^{2+}$ affects the duration of the slow component of positive movement (Fig. 6). Because this component is thought to be mediated by slippage of myosin-based adaptation motors down the stereocilia, our observations buttress previous evidence that an increased $\mathrm{Ca}^{2+}$ concentration facilitates detachment of the myosin molecules from actin (Hacohen et al., 1989; Assad and Corey, 1992). The activity of the motor is relatively unaffected by extracellular $\mathrm{Ca}^{2+}$ during the negative slow component of oscillation, when most of the channels are closed.

The decrease of the oscillation magnitude (Fig. $6 A, B$ ) in response to $\mathrm{Ca}^{2+}$ iontophoresis may readily be modeled by rendering the stiffness of some component of the gating spring sensitive to $\mathrm{Ca}^{2+}$ (Fig. 10C). Removal of extracellular $\mathrm{Ca}^{2+}$ with a chelator has the opposite effect (Figs. 6D, E, 10D).

The shift of the mean position of a bundle when the extracellular $\mathrm{Ca}^{2+}$ concentration is elevated probably results from an adaptive response to a change in the average $\mathrm{Ca}^{2+}$ concentration at the adaptation motor. Because this treatment reduces the open time of the channels, $\mathrm{Ca}^{2+}$ iontophoresis may lower the average intracellular $\mathrm{Ca}^{2+}$ concentration. The adaptation motor would then ascend the stereocilia, increasing the gating spring tension and thus evoking a negative shift. Because our model does not include a description of $\mathrm{Ca}^{2+}$ homeostasis, however, our simulation does not reproduce this effect.

When the $\mathrm{Ca}^{2+}$ concentration is either too high or too low, a hair bundle becomes quiescent. At these concentrations, the displacement-force relation of the bundle might not display an unstable region of negative stiffness (Howard and Hudspeth, 1988). Alternatively, the channel open probability at which the adaptation motors reach their steady state might lie outside the region of instability. If the open probability lies on the brink of the negative-stiffness region, however, noise would occasionally push the bundle into this region, triggering arrhythmic twitches (Fig. 6B). Because the magnitude of these twitches remains comparable with that of control oscillations, the negative-stiffness region probably persists at higher $\mathrm{Ca}^{2+}$ concentrations.

\section{Adjustment to an Hopf bifurcation}

Active hair bundle motility appears to operate near a Hopf bifurcation that separates the quiescent and spontaneously oscillatory regimens of a bundle (Martin and Hudspeth, 2001). Because a dynamical system provides optimal amplification and frequency discrimination when operating near the bifurcation (Choe et al., 1998; Eguíluz et al., 2000), it might be expected that a negativefeedback mechanism holds it there (Camalet et al., 2000). The response of an oscillatory bundle to protracted displacements indeed reveals the operation of such feedback. After having been transiently suppressed by these stimuli, spontaneous oscillation progressively resumes (Fig. 7). During recovery, the oscillation magnitude grows from zero, primarily by increasing the size of the rapid components of bundle movement. Because these components correspond to jumps across the negative-stiffness region of the displacement-force relation of the bundle (Martin et al., 2000), their magnitude depends on the breadth of this region of instability. To accord with our observations, this region must expand as the oscillation recovers. Negative stiffness arises when gating compliance dominates other elastic components in the hair bundle, so our results suggest that the gating force can be regulated.

The myosin molecules underlying adaptation could themselves be regulators of the bifurcation. A few dozen of these, apparently myosin Ic molecules (Gillespie et al., 1993; Holt et al., 2002), are thought to link each transduction channel to the actin 
Table 1. Representative parameter values of the model for spontaneous hair-bundle oscillation

\begin{tabular}{|c|c|c|c|}
\hline Parameter & Definition & Value & Reference \\
\hline$m_{\mathrm{SF}}$ & Mass of stimulus fiber & $100 \cdot 10^{-15} \mathrm{~kg}$ & Calculated from dimensions \\
\hline$\xi_{\mathrm{SF}}$ & Drag coefficient of stimulus fiber & $100 \mathrm{nN} \cdot \mathrm{sec} \cdot \mathrm{m}^{-1}$ & Measured in calibrations \\
\hline$K_{\mathrm{SF}}$ & Stiffness of stimulus fiber & $150 \mu \mathrm{N} \cdot \mathrm{m}^{-1}$ & Measured in calibrations \\
\hline$m_{\mathrm{HB}}$ & Mass of hair bundle & $60 \cdot 10^{-15} \mathrm{~kg}$ & Calculated from dimensions \\
\hline$\xi_{H B}$ & Drag coefficient of hair bundle & $130 \mathrm{nN} \cdot \mathrm{sec} \cdot \mathrm{m}^{-1}$ & Howard and Hudspeth, 1988 \\
\hline$N$ & Number of active transduction elements & 35 & Hudspeth, 1992 \\
\hline$\gamma$ & Geometrical gain of stereociliary shear motion & 0.14 & Howard and Hudspeth, 1988 \\
\hline$K_{\mathrm{SP}}$ & Stiffness of stereociliary pivots & $200 \mu \mathrm{N} \cdot \mathrm{m}^{-1}$ & Marquis and Hudspeth, 1997 \\
\hline$X_{S P}$ & Resting deflection of stereociliary pivots & $246 \mathrm{~nm}$ & Assad et al., 1991 \\
\hline$\kappa_{\mathrm{TL}}$ & Stiffness of tip link & $4000 \mu \mathrm{N} \cdot \mathrm{m}^{-1}$ & \\
\hline$d$ & Distance of gating spring relaxation on channel opening & $7 \mathrm{~nm}$ & Martin et al., 2000 \\
\hline$x_{C}$ & Resting extension of gating spring with channel closed & $12 \mathrm{~nm}$ & Hudspeth, 1992 \\
\hline$\Delta E^{\emptyset}$ & Intrinsic internal energy change on transduction channel opening & $65 \mathrm{zJ}$ & Hudspeth, 1992 \\
\hline$\kappa_{\mathrm{ES}}$ & Stiffness of extent spring & $140 \mu \mathrm{N} \cdot \mathrm{m}^{-1}$ & Shepherd and Corey, 1994; Yamoah and Gillespie, 1996 \\
\hline$x_{\mathrm{ES}}$ & Resting deflection of extent spring & $0 \mathrm{~nm}$ & \\
\hline$P_{\mathrm{Ca}}$ & $\mathrm{Ca}^{2+}$ permeability of transduction channel & $10^{-18} \mathrm{~m}^{3} \cdot \mathrm{sec}^{-1}$ & \\
\hline$Z_{C a}$ & Valence of $\mathrm{Ca}^{2+}$ & 2 & \\
\hline$V_{M}$ & Membrane potential of hair cell & $-55 \mathrm{mV}$ & Hudspeth and Lewis, 1988 \\
\hline$D_{\mathrm{Ca}}$ & Diffusion coefficient of $\mathrm{Ca}^{2+}$ in water & $800 \mu \mathrm{m}^{2} \cdot \mathrm{sec}^{-1}$ & Vanysek, 1996 \\
\hline$r_{M}$ & Distance from channel to adaptation motor & $20 \mathrm{~nm}$ & \\
\hline$C_{\text {MAX }}$ & Maximal rate constant for climbing adaptation & $0.12 \mu \mathrm{m} \cdot \sec ^{-1}$ & \\
\hline$C_{\text {MIN }}$ & Minimal rate constant for climbing adaptation & $0 \mu \mathrm{m} \cdot \sec ^{-1}$ & \\
\hline$S_{\operatorname{MAX}}$ & Maximal rate constant for slipping adaptation & $610 \mathrm{~km} \cdot \mathrm{sec}^{-1} \cdot \mathrm{N}^{-1}$ & \\
\hline$S_{\text {MIN }}$ & Minimal rate constant for slipping adaptation & $0 \mathrm{~km} \cdot \mathrm{sec}^{-1} \cdot \mathrm{N}$ & \\
\hline$k_{0 \mathrm{~N}, \mathrm{M}}$ & $\mathrm{Ca}^{2+}$-binding rate constant at adaptation motor & $10^{9} \sec ^{-1} \cdot \mathrm{m}^{-1}$ & \\
\hline$k_{0 \mathrm{OF}, \mathrm{M}}$ & $\mathrm{Ca}^{2+}$ release rate constant at adaptation motor & $200 \cdot 10^{3} \sec ^{-1}$ & \\
\hline$r_{\mathrm{RE}}$ & Distance from channel to reclosure element & $10 \mathrm{~nm}$ & \\
\hline$\kappa_{\mathrm{RE}, \mathrm{MAX}}$ & Maximal stiffness of reclosure element & $1600 \mu \mathrm{N} \cdot \mathrm{m}^{-1}$ & \\
\hline$\kappa_{\mathrm{RE}, \mathrm{MIN}}$ & Minimal stiffness of reclosure element & $100 \mu \mathrm{N} \cdot \mathrm{m}^{-1}$ & \\
\hline$k_{\mathrm{ON}, \mathrm{RE}}$ & $\mathrm{Ca}^{2+}$-binding rate constant at reclosure element & $2 \cdot 10^{9} \sec ^{-1} \cdot \mathrm{M}^{-1}$ & \\
\hline$k_{\text {OFF,RE }}$ & $\mathrm{Ca}^{2+}$-release rate constant at reclosure element & $35 \cdot 10^{3} \sec ^{-1}$ & \\
\hline
\end{tabular}

The specific values correspond to the simulation displayed in Figure 100.

core of the stereocilia. This ensemble of motors provides a dynamical elastic structure that could be part of the gating spring. Its effective stiffness would depend both on the elasticity of each element and on the fraction of motors attached to actin filaments at any time. Either of these parameters is potentially sensitive to $\mathrm{Ca}^{2+}$ : the duty cycle of adaptation motors might be regulated through the cAMP second-messenger pathway (Ricci and Fettiplace, 1997), or $\mathrm{Ca}^{2+}$ binding to calmodulin might affect the stiffness of the myosin neck (Howard and Spudich, 1996; Gillespie and Corey, 1997).

Matching the negative stiffness of a hair bundle to the positive stiffness of the load would allow the bundle to operate at a Hopf bifurcation. Because the myosin-based adaptation motors would approach a steady state under these circumstances, $\mathrm{Ca}^{2+}$-mediated reclosure of transduction channels might then power spontaneous oscillations (Choe et al., 1998). Although $\mathrm{Ca}^{2+}$ was originally posited to affect the state of transduction channels directly, channel gating could also be controlled by allowing $\mathrm{Ca}^{2+}$ to regulate the stiffness of gating springs. This arrangement would endow the gating spring with an intracellular component sensitive to $\mathrm{Ca}^{2+}$.

In the frog's sacculus, where each hair bundle is attached to an otolithic membrane, precise matching of the negative stiffness of the bundle to the positive stiffness of the membrane is improbable. The hair cell may thus require the capacity to adjust the stiffness of the bundle over a limited range. The responses shown here demonstrate that hair bundles in fact possess mechanisms for responding to various perturbations. The hair bundles of most receptor organs are attached to an accessory structure such as a tectorial or an otolithic membrane, a sallet, or a cupula. The capacity to adjust hair bundles to operate at a Hopf bifurcation may therefore prove to be a general characteristic of hair cells that ensures optimal performance.

\section{Appendix}

We modeled spontaneous hair bundle oscillations in the absence of noise by developing equations to represent four component processes: hair bundle mechanics, mechanoelectrical transduction and the associated ionic current, adaptation of the transduction process, and $\mathrm{Ca}^{2+}$-dependent channel reclosure. Here we present the essential equations of the model and explain the rationale for choosing them. We additionally provide representative values for the parameters of the model (Table 1) and cite their sources. A copy of the Mathematica program for the model is available on request.

\section{Hair bundle mechanics}

The hair bundle is represented as an elastic structure with a specific mass, moving at a low Reynolds number through a viscous medium under the influence of force delivered by an external stimulus fiber and of forces internal to the bundle. At any time, the balance of forces acting at the tip of the kinocilium, where the fiber is attached, requires that the force exerted by the stimulus fiber, $F_{\mathrm{SF}}$, be:

$$
\begin{aligned}
F_{\mathrm{SF}} & =K_{\mathrm{SF}}(\Delta-X) \\
& =\left(m_{\mathrm{HB}}+m_{\mathrm{SF}}\right) \frac{d^{2} X}{d t^{2}}+\left(\xi_{\mathrm{HB}}+\xi_{\mathrm{SF}}\right) \frac{d X}{d t} \\
& +N_{\mathrm{GS}} \gamma \kappa_{\mathrm{GS}}\left(\gamma X-x_{\mathrm{A}}+x_{\mathrm{C}}-p_{\mathrm{O}} d\right)+K_{\mathrm{SP}}\left(X-X_{\mathrm{SP}}\right),
\end{aligned}
$$


in which $X$ represents the position of the top of the bundle as well as that of the tip of the fiber (Howard and Hudspeth, 1988; Benser et al., 1996). Stimuli are applied through a fiber of stiffness $K_{\mathrm{SF}}$, whose base is displaced by a distance $\Delta$ with the stimulator. $m_{\mathrm{HB}}$ and $m_{\mathrm{SF}}$ are, respectively, the masses of the bundle and of the relevant part of the attached stimulus fiber with the entrained fluid. In the overdamped regimen germane to the present lowfrequency measurements, these masses are unimportant; they are included for the sake of completeness and to allow extension of the model to higher frequencies of stimulation. $\xi_{\mathrm{HB}}$ and $\xi_{\mathrm{SF}}$ are the corresponding drag coefficients. Because the base of the stimulus fiber was stationary during most measurements of spontaneous hair bundle motion, we have neglected an additional drag coefficient attributable to fluid flow caused by the base movements of the fiber (Martin et al., 2001). The $N_{\mathrm{GS}}$ transduction elements, each comprising a gating spring of stiffness $\kappa_{\mathrm{GS}}$ attached to the gate of a single transduction channel, are assumed to lie in parallel with one another and to experience identical mechanical inputs (Howard et al., 1988; Jacobs and Hudspeth, 1990; Iwasa and Ehrenstein, 2002). The exact distribution of channels between stereocilia and their positions with respect to the ends of tip links are immaterial to the model. The geometrical gain $\gamma$ relates the shearing motion between contiguous stereocilia, and hence gating spring extension, to movement at the top of the bundle. In the initial state of the hair bundle, the gating spring experiences an extension of $x_{C}$ when the channel is closed (Jaramillo and Hudspeth, 1993). Opening of the channel shortens the gating spring by a distance $d$; positive adaptation shortens it by an amount $x_{\mathrm{A}}$. At any instant, the open probability of the channel is $p_{\mathrm{O}}$; the total extension of the gating spring is $\gamma X-x_{\mathrm{A}}$ $+x_{\mathrm{C}}-p_{\mathrm{O}} d$. The bending of each stereocilium at its base is opposed by the elasticity of the actin fascicle that extends as a rootlet into cuticular plate (Crawford and Fettiplace, 1985; Howard and Ashmore, 1986). The stiffness of the ensemble of these stereociliary pivots is $\mathrm{K}_{\mathrm{SP}}$ (Howard and Hudspeth, 1988; Marquis and Hudspeth, 1997). When the tip links are severed, the hair bundle relaxes to the equilibrium position of those pivots, $X_{\mathrm{SP}}$ (Howard et al., 1988; Assad et al., 1991).

\section{Mechanoelectrical transduction and $\mathrm{Ca}^{2+}$ entry}

The gating of the transduction channels in a hair bundle is described by the gating spring model (Corey and Hudspeth, 1983) (for review, see Howard et al., 1988; Hudspeth, 1992; Markin and Hudspeth, 1995; Hudspeth et al., 2000). The open probability of each transduction channel is:

$$
p_{\mathrm{O}}=\frac{1}{1+e^{\left[\Delta E^{\emptyset}-\kappa_{\mathrm{GS}} d\left(\gamma X-x_{A}+x_{\mathrm{C}}-d / 2\right)\right] /(k T)}} .
$$

The intrinsic internal energy change associated with channel gating, $\Delta \mathrm{E}^{\wp}$, reflects the increase in energy content of a channel when it moves from the closed to the open state in the absence of a gating spring. $k$ is the Boltzmann constant, and $T$ is the temperature. Because of the rapidity of transduction on the time scale of the oscillations studied here (Corey and Hudspeth, 1983), a description of the kinetics of gating is unnecessary, and this equilibrium formulation of the open probability suffices.

The very low cytoplasmic concentration of $\mathrm{Ca}^{2+}$ virtually precludes outward current carried by that ion, so it is unrealistic to describe the $\mathrm{Ca}^{2+}$ current through an open transduction chan- nel, $I_{\mathrm{Ca}}$, in terms of a conductance and driving force. We instead use the Goldman-Hodgkin-Katz current equation (Hille, 1992):

$$
I_{\mathrm{Ca}}=\frac{p_{O} P_{\mathrm{Ca}} z_{\mathrm{Ca}}^{2} e F V_{\mathrm{M}}\left[\mathrm{Ca}^{2+}\right]}{k T\left[1-e^{\left(z_{\mathrm{Ca} e} V_{\mathrm{M}}\right) /(k T)}\right]} .
$$

Here $P_{\mathrm{Ca}}$ is the $\mathrm{Ca}^{2+}$ permeability, $z_{\mathrm{Ca}}$ is the valence of the ion, $e$ is the electron charge, $F$ is the Faraday constant, $\left[\mathrm{Ca}^{2+}\right]$ is the $\mathrm{Ca}^{2+}$ concentration in endolymph, and $V_{\mathrm{M}}$ is the membrane potential.

$\mathrm{Ca}^{2+}$ that enters the stereociliary cytoplasm through transduction channels is subject to buffering and extrusion (Lumpkin and Hudspeth, 1998; Ricci et al., 1998; Yamoah et al., 1998). The mean time to capture by buffer molecules, however, is great enough that buffering has little effect within $\sim 100 \mathrm{~nm}$ of a channel (Roberts, 1993, 1994). Because an insertional plaque is only $\sim 50 \mathrm{~nm}$ in diameter, we may assume that the $\mathrm{Ca}^{2+}$-binding sites responsible for regulating motor activity are essentially exposed to $\mathrm{Ca}^{2+}$ diffusing from a point source, the channel, into a semiinfinite volume. For a motor at a distance $r_{M}$ from the channel, the steady-state $\mathrm{Ca}^{2+}$ concentration is then (Berg, 1993):

$$
\left[\mathrm{Ca}^{2+}\right]=\frac{-I_{\mathrm{Ca}}}{2 \pi z_{\mathrm{Ca}} F D_{\mathrm{Ca}} r_{\mathrm{M}}},
$$

in which $D_{\mathrm{Ca}}$ is the diffusion coefficient of $\mathrm{Ca}^{2+}$. This steadystate concentration is mostly achieved within a few tens of microseconds (Lumpkin and Hudspeth, 1998).

\section{Adaptation}

Adaptation of the mechanoelectrical transduction process (for review, see Hudspeth and Gillespie, 1994; Eatock, 2000; Holt and Corey, 2000) is assumed to result from movement of the insertional plaque at the upper end of each tip link (Howard and Hudspeth, 1987a,b). This movement is affected by two countervailing influences, the downward pull of the extended gating spring and the ascent of the myosin-based molecular motor at the insertional plaque (Assad and Corey, 1992). In addition, the insertional plaque is anchored to the stereociliary cytoskeleton by an elastic extent spring that renders adaptation incomplete (Shepherd and Corey, 1994; Yamoah and Gillespie, 1996). The rate of adaptation is:

$$
\frac{d x_{\mathrm{A}}}{d t}=-C+S\left[\kappa_{\mathrm{GS}}\left(\gamma X-x_{\mathrm{A}}+x_{\mathrm{C}}-p_{\mathrm{O}} d\right)-\kappa_{\mathrm{ES}}\left(x_{\mathrm{A}}+x_{\mathrm{ES}}\right)\right],
$$

in which $C$ is the rate constant for climbing adaptation (myosindriven upward movement of the insertional plaque), and $S$ is that for slipping adaptation (downward motion attributable to tension in the gating spring). A positive value for $x_{\mathrm{A}}$, which reflects a decrease in gating spring tension, corresponds to movement down the stereocilium. With the hair bundle in its initial position, the insertional plaque is located a distance $x_{\mathrm{ES}}$ below the cytoskeletal attachment of an extent spring of stiffness $\kappa_{\mathrm{ES}}$.

The rate of adaptation depends on the stereociliary $\mathrm{Ca}^{2+}$ concentration (Eatock et al., 1987; Crawford et al., 1989; Hacohen et al., 1989). Although the explicit dependence has not been measured, it appears that the value of the parameter $S$ increases and that of the parameter $C$ declines with an elevation of the $\mathrm{Ca}^{2+}$ concentration (Assad and Corey, 1992; Shepherd and Corey, 1994). We suppose that $\mathrm{Ca}^{2+}$ binds to calmodulin (Walker et al., 1993; Walker and Hudspeth, 1996) attached at the two, three, or possibly four IQ domains of each myosin Ic molecule at the ad- 
aptation motor (Metcalf et al., 1994; Solc et al., 1994). Although this ensemble of calmodulin molecules could potentially bind as many as 16 ions, we consider for the sake of simplicity only unimolecular binding at any of a single class of sites, characterized by an $\mathrm{ON}$ rate constant, $k_{\mathrm{ON}, \mathrm{M}}$, and an OFF rate constant, $k_{\mathrm{OFF}, \mathrm{M}}$, and hence by a dissociation constant, $K_{\mathrm{D}, \mathrm{M}}$. The probability of $\mathrm{Ca}^{2+}$ binding, $p_{\mathrm{B}}$, changes at the rate:

$$
\frac{d p_{\mathrm{B}, \mathrm{M}}}{d t}=k_{\mathrm{ON}, \mathrm{M}}\left[\mathrm{Ca}^{2+}\right]\left(1-p_{\mathrm{B}, \mathrm{M}}\right)-k_{\mathrm{OFF}, \mathrm{M}} p_{\mathrm{B}, \mathrm{M}} .
$$

At equilibrium, the binding probability is:

$$
p_{\mathrm{B} . \mathrm{M}}=\frac{1}{1+\left(\frac{k_{\mathrm{OFF}, \mathrm{M}}}{k_{\mathrm{ON}, \mathrm{M}}\left[\mathrm{Ca}^{2+}\right]}\right)}=\frac{1}{1+\left(\frac{K_{\mathrm{D}, \mathrm{M}}}{\left[\mathrm{Ca}^{2+}\right]}\right)} .
$$

The activity of the adaptation motor in turn depends on the extent of $\mathrm{Ca}^{2+}$ binding at the regulatory site. The rate constant for climbing adaptation is governed by the relation:

$$
C=\left(1-p_{\mathrm{B}, \mathrm{M}}\right)\left(C_{\mathrm{MAX}}-C_{\mathrm{MIN}}\right)+C_{\mathrm{MIN}} \cdot
$$

Slipping adaptation is described by:

$$
S=p_{\mathrm{B}, \mathrm{M}}\left(S_{\mathrm{MAX}}-S_{\mathrm{MIN}}\right)+S_{\mathrm{MIN}} \text {. }
$$

\section{$\mathrm{Ca}^{2+}$-dependent channel reclosure}

The reclosure of a mechanoelectrical transduction channel under the influence of $\mathrm{Ca}^{2+}$ was initially hypothesized to occur when $\mathrm{Ca}^{2+}$ binds directly to the channel itself or to a closely coupled protein and alters the energy difference between the closed and open states of the channel (Howard and Hudspeth, 1988; Jaramillo et al., 1990). Subsequent modeling has been based on this mechanism (Choe et al., 1998; Wu et al., 1999). In the present instance, we hypothesize instead that $\mathrm{Ca}^{2+}$ in the stereociliary cytoplasm does not force a channel to shut but allows it to close. More specifically, we consider that the binding of $\mathrm{Ca}^{2+}$ reduces the gating spring tension that promotes channel opening and thereby fosters reclosure. Three considerations motivate this formulation. First, when hair bundles are immersed in standard saline solution, the fast positive phase of their movement in response to transient mechanical stimulation (Benser et al., 1996) may reflect a rapid relaxation event in addition to a passive elastic response. Next, $\mathrm{Ca}^{2+}$-induced relaxation of an element in the transduction machinery provides an explanation for electrically evoked hair bundle movements (Bozovic and Hudspeth, 2003). Finally, the changes in oscillation amplitude observed in the present study imply a mechanism that alters the shape of the displacement-force relation of the hair bundle. Although there may be several ways in which such a change could occur, we elected to use in the model a representation consistent with the two foregoing observations. Our formulation is not meant to preclude the possibility that the binding of $\mathrm{Ca}^{2+}$ to the transduction channel also promotes channel reclosure more directly, but that possibility is not required in the present simulations.

We represent each gating spring as two components in series. The extracellular component is the tip link, whose stiffness, $\kappa_{\mathrm{TL}}$, might be quite high (Kachar et al., 2000). The intracellular reclosure element, of stiffness $\kappa_{\mathrm{RE}}$, might represent the elasticity of the neck domains of myosin Ic molecules at the insertional plaque (Howard and Spudich, 1996; Gillespie and Corey, 1997). Another possibility is that the stiffness of this element reflects the number of these molecules attached in parallel to the actin cytoskeleton at any time. In either event, the two elements lie in series and the overall stiffness of each gating spring is:

$$
\kappa_{\mathrm{GS}}=\frac{\kappa_{\mathrm{TL}} \kappa_{\mathrm{RE}}}{\kappa_{\mathrm{TL}}+\kappa_{\mathrm{RE}}} .
$$

The stiffness of the reclosure element depends on the probability of $\mathrm{Ca}^{2+}$ binding there. The $\mathrm{Ca}^{2+}$ concentration at a reclosure element located a distance $r_{\mathrm{RE}}$ from a transduction channel is given by Equation 8, with the term $r_{\mathrm{RE}}$ substituted for $r_{\mathrm{M}}$; the subscript RE denotes the reclosure element. The probability of $\mathrm{Ca}^{2+}$ binding varies with time according to Equation 10, and the associated equilibrium binding probability is given by Equation 11 , again with the substitution of subscripts.

For the sake of simplicity, we suppose that the stiffness of the reclosure element varies linearly between a maximal and a minimal value, respectively $\kappa_{\mathrm{RE}, \mathrm{MAX}}$ and $\kappa_{\mathrm{RE}, \mathrm{MIN}}$, in proportion to the probability that $\mathrm{Ca}^{2+}$ is bound, $p_{\mathrm{B}, \mathrm{RE}}$ :

$$
\kappa_{\mathrm{RE}}=\left(1-p_{\mathrm{B}, \mathrm{RE}}\right)\left(\kappa_{\mathrm{RE}, \mathrm{MAX}}-\kappa_{\mathrm{RE}, \mathrm{MIN}}\right)+\kappa_{\mathrm{RE}, \mathrm{MIN}} \cdot
$$

\section{References}

Assad JA, Corey DP (1992) An active motor model for adaptation by vertebrate hair cells. J Neurosci 12:3291-3309.

Assad JA, Shepherd GMG, Corey DP (1991) Tip-link integrity and mechanical transduction in vertebrate hair cells. Neuron 7:985-994.

Benser ME, Issa NP, Hudspeth AJ (1993) Hair-bundle stiffness dominates the elastic reactance to otolithic-membrane shear. Hear Res 68:243-252.

Benser ME, Marquis RE, Hudspeth AJ (1996) Rapid, active hair-bundle movements in hair cells from the bullfrog's sacculus. J Neurosci 16:5629-5643.

Berg HC (1993) Random walks in biology, Expanded Ed, p 23. Princeton, NJ: Princeton UP.

Bowen RE (1931) Movement of the so-called hairs in the ampullar organs of fish ears. Proc Natl Acad Sci USA 17:192-194.

Bozovic D, Hudspeth AJ (2003) Hair-bundle movements elicited by transepithelial electrical stimulation of hair cells in the sacculus of the bullfrog. Proc Natl Acad Sci USA 100:958-963.

Camalet S, Jülicher F, Prost J (1999) Self-organized beating and swimming of internally driven filaments. Phys Rev Lett 82:1590-1593.

Camalet S, Duke T, Jülicher F, Prost J (2000) Auditory sensitivity provided by self-tuned critical oscillations of hair cells. Proc Natl Acad Sci USA 97:3183-3188.

Choe Y, Magnasco M, Hudspeth AJ (1998) A model for amplification of hair-bundle motion by cyclical binding of $\mathrm{Ca}^{2+}$ to mechanoelectrical transduction channels. Proc Natl Acad Sci USA 95:15321-15326.

Corey DP, Hudspeth AJ (1983) Kinetics of the receptor current in bullfrog saccular hair cells. J Neurosci 3:962-976.

Cramer LP, Mitchison TJ (1995) Myosin is involved in postmitotic cell spreading. J Cell Biol 131:179-189.

Crawford AC, Fettiplace R (1985) The mechanical properties of ciliary bundles of turtle cochlear hair cells. J Physiol (Lond) 364:359-379.

Crawford AC, Evans MG, Fettiplace R (1989) Activation and adaptation of transducer currents in turtle hair cells. J Physiol (Lond) 419:405-434.

Crawford AC, Evans MG, Fettiplace R (1991) The actions of calcium on the mechano-electrical transducer current of turtle hair cells. J Physiol (Lond) 434:369-398.

Dallos P (1992) The active cochlea. J Neurosci 12:4575-4585.

Denk W, Webb WW (1992) Forward and reverse transduction at the limit of sensitivity studied by correlating electrical and mechanical fluctuations in frog saccular hair cells. Hear Res 60:89-102.

Denk W, Keolian R, Webb WW (1992) Mechanical response of frog saccular hair bundles to the aminoglycoside block of mechanoelectrical transduction. J Neurophysiol 68:927-932.

Eatock RA (2000) Adaptation in hair cells. Annu Rev Neurosci 23:285-314.

Eatock RA, Corey DP, Hudspeth AJ (1987) Adaptation of mechanoelectrical transduction in hair cells of the bullfrog's sacculus. J Neurosci 7:2821-2836.

Eguíluz VM, Ospeck M, Choe Y, Hudspeth AJ, Magnasco MO (2000) Essential nonlinearities in hearing. Phys Rev Lett 84:5232-5235. 
Fabiato A, Fabiato F (1979) Calculator programs for computing the composition of the solutions containing multiple metals and ligands. J Physiol (Paris) 75:463-505.

Fettiplace R, Ricci AJ, Hackney CM (2001) Clues to the cochlear amplifier from the turtle ear. Trends Neurosci 24:169-175.

Géléoc GSG, Corey DP (2001) Modulation of mechanoelectrical transduction by protein kinase A in utricular hair cells of neonatal mice, Abstract 21903, 2001 Midwinter Meeting of the Association for Research in Otolaryngology, St. Petersburg Beach, FL.

Gillespie PG, Corey DP (1997) Myosin and adaptation by hair cells. Neuron 19:955-958.

Gillespie PG, Wagner MC, Hudspeth AJ (1993) Identification of a $120 \mathrm{kd}$ hair-bundle myosin located near stereociliary tips. Neuron 11:581-594.

Hacohen N, Assad JA, Smith WJ, Corey DP (1989) Regulation of tension on hair-cell transduction channels: displacement and calcium dependence. J Neurosci 9:3988-3997.

He DZ, Beisel KW, Chen L, Ding DL, Jia S, Fritzsch B, Salvi R (2003) Chick hair cells do not exhibit voltage-dependent somatic motility. J Physiol (London) 546:511-520.

Herrmann C, Wray J, Travers F, Barman T (1992) Effect of 2,3-butanedione monoxime on myosin and myofibrillar ATPases. An example of an uncompetitive inhibitor. Biochemistry 31:12227-12232.

Hille B (1992) Ionic channels of excitable membranes, Ed 2, p 342. Sunderland, MA: Sinauer.

Hillman DE, Lewis ER (1971) Morphological basis for a mechanical linkage in otolithic receptor transduction in the frog. Science 174:416-419.

Holt JR, Corey DP (2000) Two mechanisms for transducer adaptation in vertebrate hair cells. Proc Natl Acad Sci USA 97:11730-11735.

Holt JR, Gillespie SKH, Provance Jr DW, Shah K, Shokat KM, Corey DP, Mercer JA, Gillespie PG (2002) A chemical-genetic strategy implicates myosin-1c in adaptation by hair cells. Cell 108:371-381.

Holton T, Hudspeth AJ (1986) The transduction channel of hair cells from the bull-frog characterized by noise analysis. J Physiol (Lond) 375:195-227.

Howard J, Ashmore JF (1986) Stiffness of sensory hair bundles in the sacculus of the frog. Hear Res 23:93-104.

Howard J, Hudspeth AJ (1987a) Mechanical relaxation of the hair bundle mediates adaptation in mechanoelectrical transduction by the bullfrog's saccular hair cell. Proc Natl Acad Sci USA 84:3064-3068.

Howard J, Hudspeth AJ (1987b) Adaptation of mechanoelectrical transduction in hair cells. In: Sensory transduction (Hudspeth AJ, MacLeish PR, Margolis FL, Wiesel TN, eds), pp 138-145. Geneva: Fondation pour l'Etude du Système Nerveux Central et Périphérique.

Howard J, Hudspeth AJ (1988) Compliance of the hair bundle associated with gating of mechanoelectrical transduction channels in the bullfrog's saccular hair cell. Neuron 1:189-199.

Howard J, Spudich JA (1996) Is the lever arm of myosin a molecular elastic element? Proc Natl Acad Sci USA 93:4462-4464.

Howard J, Roberts WM, Hudspeth AJ (1988) Mechanoelectrical transduction by hair cells. Annu Rev Biophys Biophys Chem 17:99-124.

Hudspeth AJ (1992) Hair-bundle mechanics and a model for mechanoelectrical transduction by hair cells. In: Sensory transduction (Corey DP, Roper SD, eds), pp 357-370. New York: Rockefeller UP.

Hudspeth AJ (1997) Mechanical amplification of stimuli by hair cells. Curr Opin Neurobiol 7:480-486.

Hudspeth AJ, Gillespie PG (1994) Pulling springs to tune transduction: adaptation by hair cells. Neuron 12:1-9.

Hudspeth AJ, Jacobs R (1979) Stereocilia mediate transduction in vertebrate hair cells. Proc Natl Acad Sci USA 76:1506-1509.

Hudspeth AJ, Lewis RS (1988) A model for electrical resonance and frequency tuning in saccular hair cells of the bull-frog, Rana catesbeiana. J Physiol (Lond) 400:275-297.

Hudspeth AJ, Choe Y, Mehta AD, Martin P (2000) Putting ion channels to work: mechanoelectrical transduction, adaptation, and amplification by hair cells. Proc Natl Acad Sci USA 97:11765-11772.

Igarashi M, Kashiwagi K (2000) Polyamines: mysterious modulators of cellular functions. Biochem Biophys Res Commun 271:559-564.

Iwasa KH, Ehrenstein G (2002) Cooperative interaction as the physical basis of the negative stiffness in hair cell stereocilia. J Acoust Soc Am 111:2208-2212.

Jacobs RA, Hudspeth AJ (1990) Ultrastructural correlates of mechanoelec- trical transduction in hair cells of the bullfrog's internal ear. Cold Spring Harb Symp Quant Biol 55:547-561.

Jaramillo F, Hudspeth AJ (1991) Localization of the hair cell's transduction channels at the hair bundle's top by iontophoretic application of a channel blocker. Neuron 7:409-420.

Jaramillo F, Hudspeth AJ (1993) Displacement-clamp measurement of the forces exerted by gating springs in the hair bundle. Proc Natl Acad Sci USA 90:1330-1334.

Jaramillo F, Howard J, Hudspeth AJ (1990) Calcium ions promote rapid mechanically evoked movements of hair bundles. In: The mechanics and biophysics of hearing (Dallos P, Geisler CD, Matthews JW, Ruggero MA, Steele CR, eds), pp 26-33. Berlin: Springer.

Jülicher F, Andor D, Duke T (2001) Physical basis of two-tone interference in hearing. Proc Natl Acad Sci USA 98:9080-9085.

Kachar B, Parakkal M, Fex J (1990) Structural basis for mechanical transduction in the frog vestibular sensory apparatus: I. The otolithic membrane. Hear Res 45:179-190.

Kachar B, Parakkal M, Kurc M, Zhao Y, Gillespie PG (2000) Highresolution structure of hair-cell tip links. Proc Natl Acad Sci USA 97:13336-13341.

Koyama H, Lewis ER, Leverenz EL, Baird RA (1982) Acute seismic sensitivity in the bullfrog ear. Brain Res 250:168-172.

Kroese ABA, Das A, Hudspeth AJ (1989) Blockage of the transduction channels of hair cells in the bullfrog's sacculus by aminoglycoside antibiotics. Hear Res 37:203-218.

Lumpkin EA, Hudspeth AJ (1998) Regulation of free $\mathrm{Ca}^{2+}$ concentration in hair-cell stereocilia. J Neurosci 18:6300-6318.

Manley GA (2000) Cochlear mechanisms from a phylogenetic viewpoint. Proc Natl Acad Sci USA 97:11736-11743.

Manley GA (2001) Evidence for an active process and a cochlear amplifier in nonmammals. J Neurophysiol 86:541-549.

Manley GA, Kirk DL (2002) BAPTA reduces the frequency of spontaneous otoacoustic emissions in lizards, Abstract 321, 2002 Midwinter Meeting of the Association for Research in Otolaryngology, St. Petersburg Beach, FL.

Manley GA, Köppl C (1998) Phylogenetic development of the cochlea and its innervation. Curr Opin Neurobiol 8:468-474.

Markin VS, Hudspeth AJ (1995) Gating-spring models of mechanoelectrical transduction by hair cells of the internal ear. Annu Rev Biophys Biomol Struct 24:59-83.

Marquis RE, Hudspeth AJ (1997) Effects of extracellular $\mathrm{Ca}^{2+}$ concentration on hair-bundle stiffness and gating-spring integrity in hair cells. Proc Natl Acad Sci USA 94:11923-11928.

Martin P, Hudspeth AJ (1999) Active hair-bundle movements can amplify a hair cell's response to oscillatory mechanical stimuli. Proc Natl Acad Sci USA 96:14306-14311.

Martin P, Hudspeth AJ (2001) Compressive nonlinearity in the hair bundle's active response to mechanical stimulation. Proc Natl Acad Sci USA 98:14386-14391.

Martin P, Mehta AD, Hudspeth AJ (2000) Negative hair-bundle stiffness betrays a mechanism for mechanical amplification by the hair cell. Proc Natl Acad Sci USA 97:12026-12031.

Martin P, Hudspeth AJ, Jülicher F (2001) Comparison of a hair bundle's spontaneous oscillations with its response to mechanical stimulation reveals the underlying active process. Proc Natl Acad Sci USA 98:14380-14385.

Metcalf AB, Chelliah Y, Hudspeth AJ (1994) Molecular cloning of a myosin $\mathrm{I} \beta$ isozyme that may mediate adaptation by hair cells of the bullfrog's internal ear. Proc Natl Acad Sci USA 91:11821-11825.

Nobili R, Mammano F, Ashmore J (1998) How well do we understand the cochlea? Trends Neurosci 21:159-167.

Ostap EM (2002) 2,3-Butanedione monoxime (BDM) as a myosin inhibitor. J Muscle Res Cell Motil 23:305-308.

Ricci AJ, Fettiplace R (1997) The effects of calcium buffering and cyclic AMP on mechano-electrical transduction in turtle auditory hair cells. J Physiol (Lond) 501:111-124.

Ricci AJ, Wu Y-C, Fettiplace R (1998) The endogenous calcium buffer and the time course of transducer adaptation in auditory hair cells. J Neurosci 18:8261-8277.

Ricci AJ, Crawford AC, Fettiplace R (2000) Active hair bundle motion linked to fast transducer adaptation in auditory hair cells. J Neurosci 20:7131-7142. 
Ricci AJ, Crawford AC, Fettiplace R (2002) Mechanisms of active hair bundle motion in auditory hair cells. J Neurosci 22:44-52.

Roberts WM (1993) Spatial calcium buffering in saccular hair cells. Nature 363:74-76

Roberts WM (1994) Localization of calcium signals by a mobile calcium buffer in frog saccular hair cells. J Neurosci 14:3246-3262.

Ruggero MA, Rich NC, Robles L (1997) Basilar-membrane response to tones at the base of the chinchilla cochlea 104:2151-2163.

Rüsch A, Thurm U (1990) Spontaneous and electrically induced movements of ampullary kinocilia and stereovilli. Hear Res 48:247-264.

Seow CY, Shroff SG, Ford LE (1997) Detachment of low-force bridges contributes to the rapid tension transients of skinned rabbit skeletal muscle fibres. J Physiol (Lond) 501:149-164.

Shepherd GMG, Corey DP (1994) The extent of adaptation by bullfrog saccular hair cells. J Neurosci 14:6217-6229.

Solc CK, Derfler BH, Duyk GM, Corey DP (1994) Molecular cloning of myosins from the bullfrog saccular macula: a candidate for the hair cell adaptation motor. Aud Neurosci 1:63-75.

Strogatz SH (1994) Nonlinear dynamics and chaos, pp 211-215. Reading, MA: Addison-Wesley.

Tesi C, Colomo F, Piroddi N, Poggesi C (2002) Characterization of the cross-bridge force-generating step using inorganic phosphate and BDM in myofibrils from rabbit skeletal muscles. J Physiol (Lond) 541:187-199.
Titus MA (2003) Caveat experimentor-is your myosin really inhibited? Nat Cell Biol 5:95.

Tucker TR, Fettiplace R (1996) Monitoring calcium in turtle hair cells with a calcium-activated potassium channel. J Physiol (Lond) 494:613-626.

Vanysek P (1996) Ionic conductivity and diffusion at infinite dilution. In: Handbook of chemistry and physics, Ed 77 (Lide DR, ed) pp 5-98. Boca Raton, FL: CRC.

Walker RG, Hudspeth AJ (1996) Calmodulin controls adaptation of mechanoelectrical transduction by hair cells of the bullfrog's sacculus. Proc Nat Acad Sci USA 93:2203-2207.

Walker RG, Hudspeth AJ, Gillespie PG (1993) Calmodulin and calmodulinbinding proteins in hair bundles. Proc Natl Acad Sci USA 90:2807-2811.

Wu Y-C, Ricci AJ, Fettiplace R (1999) Two components of transducer adaptation in auditory hair cells. J Neurophysiol 82:2171-2181.

Yamoah EN, Gillespie PG (1996) Phosphate analogs block adaptation in hair cells by inhibiting adaptation-motor force production. Neuron 17:523-533.

Yamoah EN, Lumpkin EA, Dumont RA, Smith PJS, Hudspeth AJ, Gillespie PG (1998) Plasma-membrane $\mathrm{Ca}^{2+}$-ATPase extrudes $\mathrm{Ca}^{2+}$ from haircell stereocilia. J Neurosci 18:610-624.

Yu X, Lewis ER, Feld D (1991) Seismic and auditory tuning curves from bullfrog saccular and amphibian papillar axons. J Comp Physiol [A] 169:241-248. 